Vol.17, No. 62, January, 2022,406 -419

\title{
ASSESSING THE SUITABILITY OF EXTERNAL SPACES OF EDUCATIONAL SCHOOLS IN EGYPT FOR THE MOTOR DISABLED (A CASE STUDY: FUTURE INTERNATIONAL SCHOOL IN LUXOR)
}

\author{
Mohamed Ahmed Mohamed*1, Abbas Mahmoud Abbas ${ }^{1}$ and Mostafa Bogdady ${ }^{2}$ \\ ${ }^{1}$ Architecture Engineering Department, Faculty of Eng., Al- Azhar University, Qena, Egypt. \\ ${ }^{2}$ Architecture Engineering Department, Faculty Of Eng., Al- Azhar University, Cairo, Egypt. \\ *Corresponding Author E-mail: En.mohamedsaleh@gmail.com
}

Received :2 Nov. $2021 \quad$ Accepted:5 Dec. 2021

\begin{abstract}
:
Studying the concept of disability and the description and analysis of the problems that can face the physically disabled persons in the built environment are considered one of the most important issues that have not received sufficient attention by specialists in the field of architecture and urbanism. Actually, the physically disabled people face many barriers in Egyptian schools so that they can't easily participate in society. So, it may lead them to isolation or exposure to more disabilities or accidents. Accordingly, this may affect their education, especially in light of the programs of integrating people with physical disabilities with healthy ones in one school. Therefore, removing those obstacles is one of the most important priorities of effective architectural work towards various disability issues. The research paper aimed to identify the spaces constituting the external environment in school buildings in Egypt through studying the state of the external spaces at the Future International School in Luxor, and to check their suitability to the requirements of the Egyptian code of the physically disabled. Further, the research aimed at monitoring the barriers that do not meet the functional requirements of people with physical disabilities, and studying the impact of those barriers on different groups of physically disabled children or adults. The research results revealed that the components of the external spaces at the Future International School meet the requirements of the Egyptian Code for the Disabled by $38 \%$, and that $44 \%$ of the requirements have not been met. Further, $18 \%$ of the requirements exist, but they do not conform to the requirements of the code. Also, the results showed that those barriers have a very weak impact on the impaired persons in the upper extremities, while the impact is more severe on those who are impaired in the lower extremities, especially wheelchair users. Finally, the barriers are represented in the paths, external roads, slopes and the external stairs of the school.
\end{abstract}

keywords: the disability; disabled persons; international schools; Obstacles of the built environment. 


\title{
تقييم ملاءمة الفراغات الخارجية بالمدارس التعليمية بمصر لذوى الإعاقة الحركية

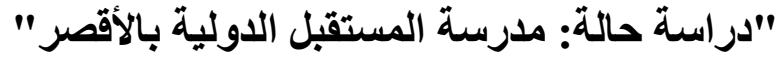

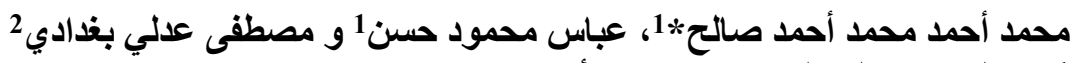

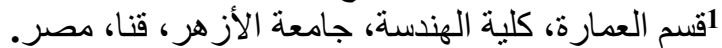

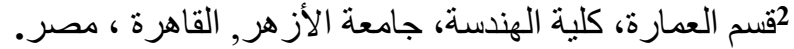

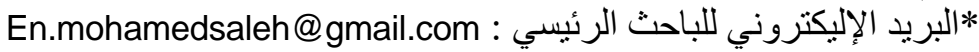

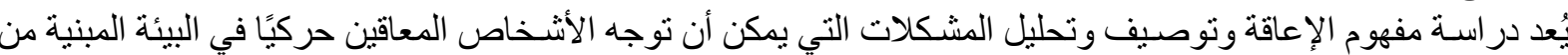

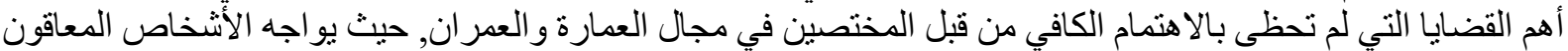

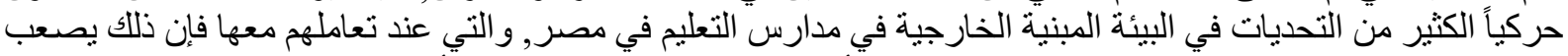

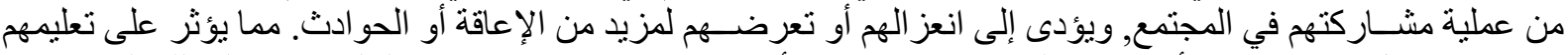

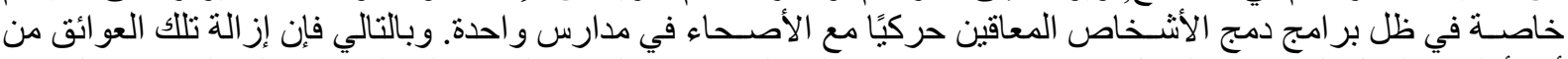

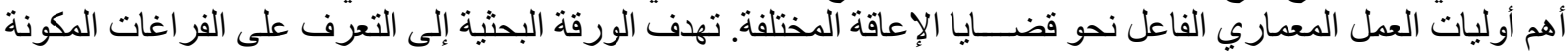

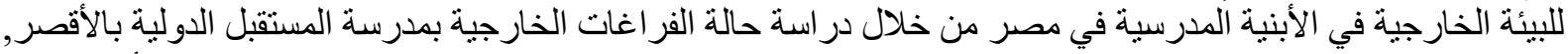

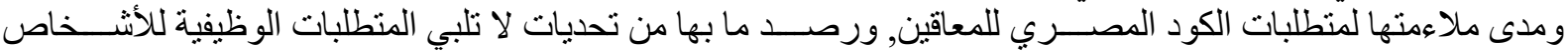

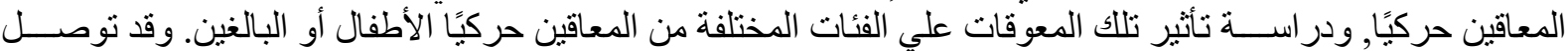

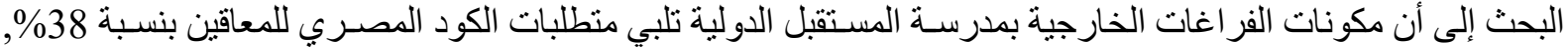

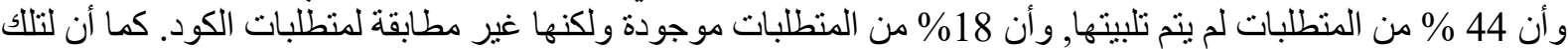

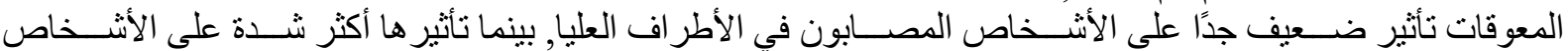

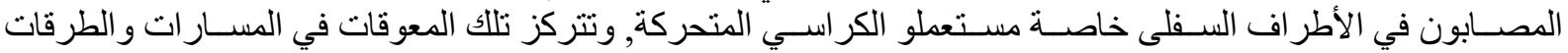

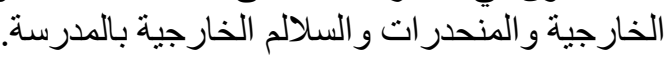
الكلمات المفتاحية: الإعاقة؛ الأشخاص المعاقون؛ مدارسة المدارس التعليم الدولية؛ معوقات البيئة المبنية.

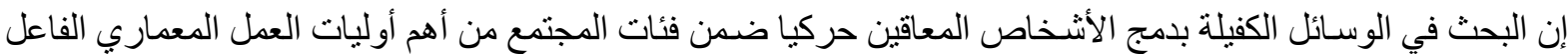

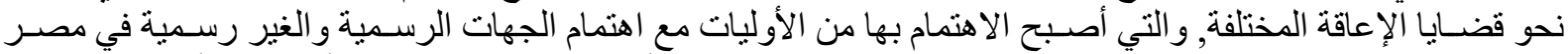

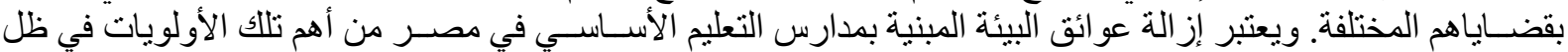

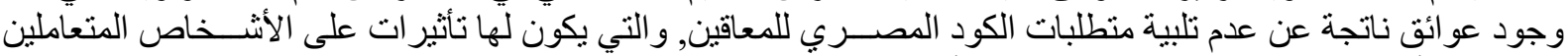

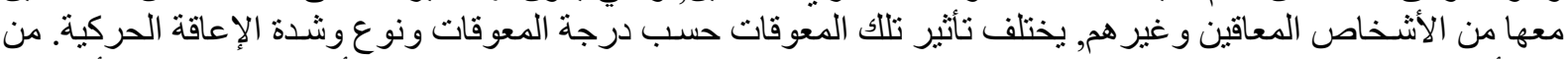

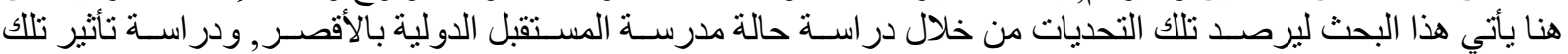
المعوقات على الفئات المختلفة من الأشخاص المعاقين حركيا.

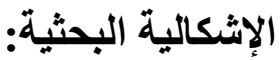

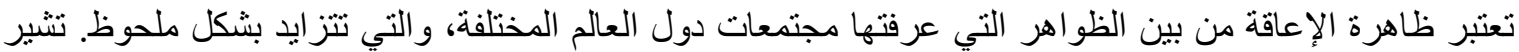

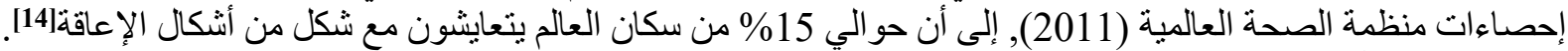

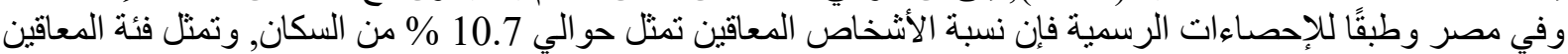

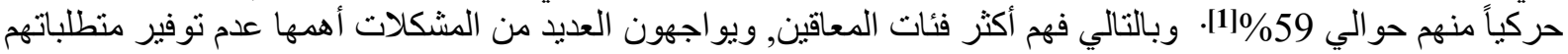

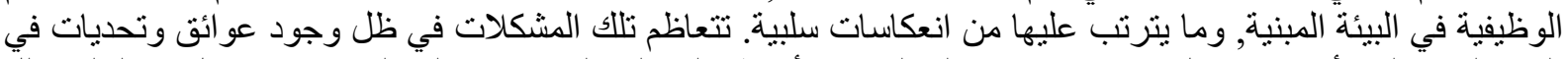

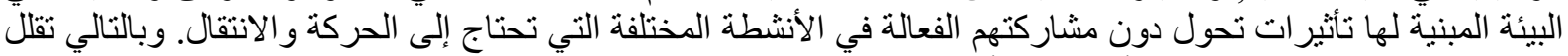

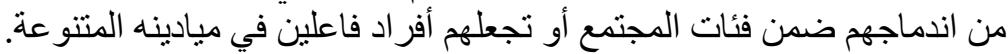

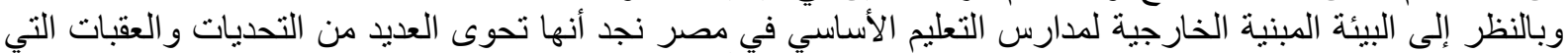

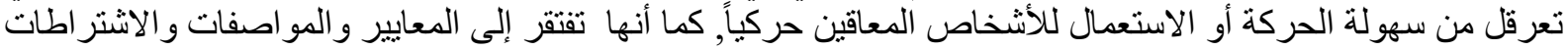

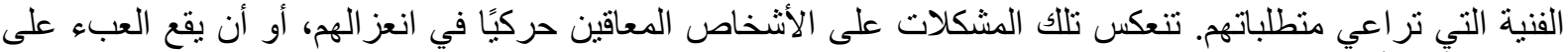

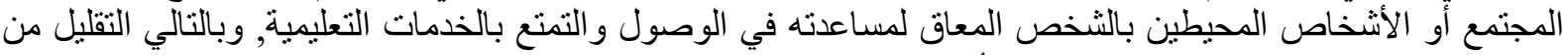
فرص اندماجهم ضمن فئات المجتمع وجعلهم أفر ادًا فاعلين فيه.

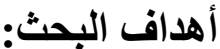
• در اسـة التحديات و الصعوبات التي يو اجهها الأشخاص المعاقين حركياً في الفر اغات الخارجية لأبنية مدارس التعليم في مصر من خلال در اسة حالة مدرسة المستقبل الدولية بالأقصر . 
تقييم ملاءمة الفر اغات الخارجية بالمدارس التعليمية بمصر لذوى الإعاقة الحركية "دراسة حالة: مدرسة المستقبل الدولية بالأقصر"

• تحديد مدى تطبيق منطلبات الأثـــخاص المعاقين حركيًا في الفر اغات الخارجية بمدارس التعليم الدولية, و الواردة بالكود المصري للمعاقين.

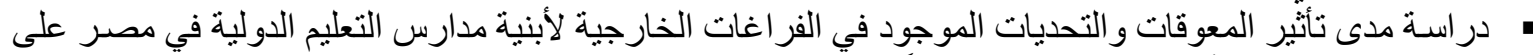

الفئات المختلفة من الأشخاص المعات المعين حركياً.

$$
\text { فرضية البحث: }
$$

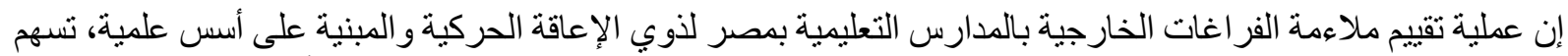
في وضع تصور كامل لمشكلة المعاقين حركيًا في البيئة المدرسية، وتعتبر تحديات البيئة المبنية من أكبر العوائق التي التي التياتي

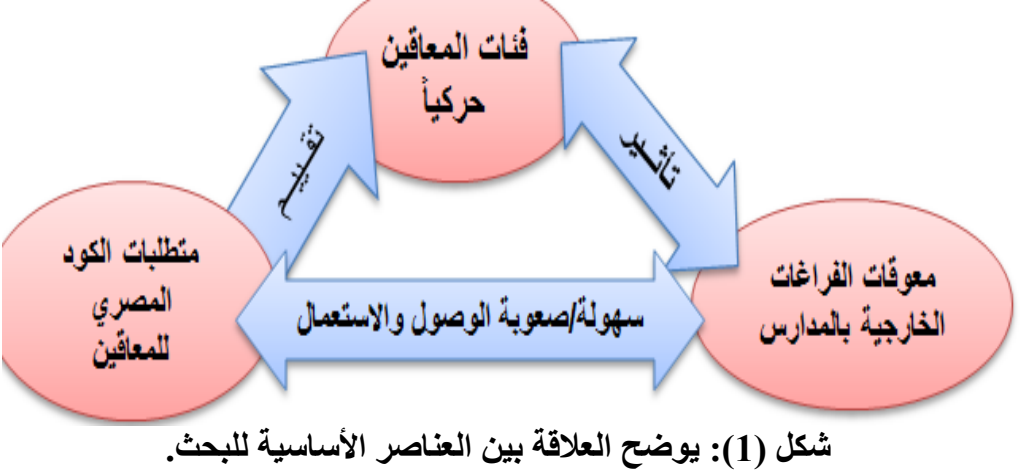

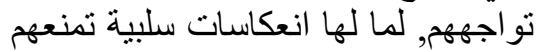

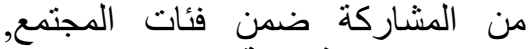
وبالتالي تكون فرضية البحث كتالي.

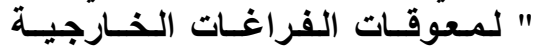

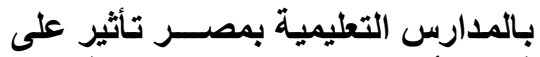

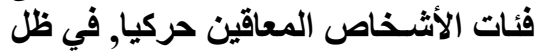

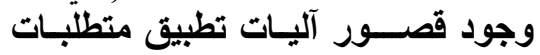

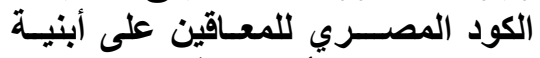
مدارس التعليم الأسـاسي في مصر لمع " كما

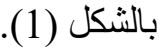

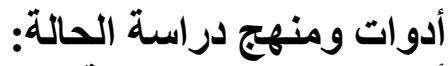

أعتمد الباحث على مجموعة من الدئة الأدوات والوسائل التي تمكنه من تحقيق أهداف البحث من خلال منهجية متكامل من ثلاثة

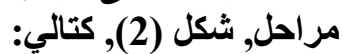

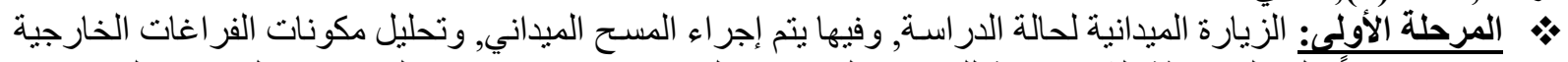

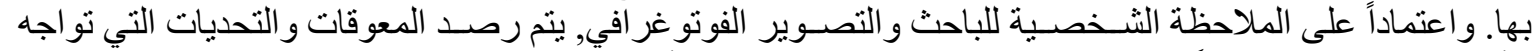

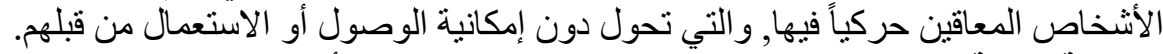

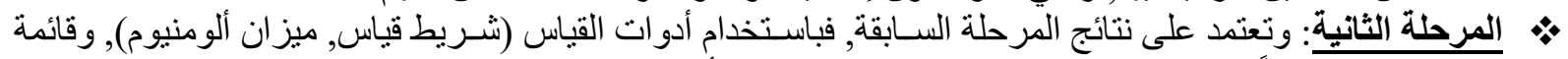

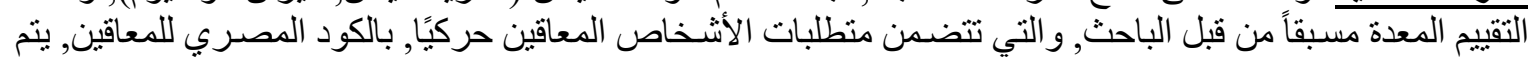

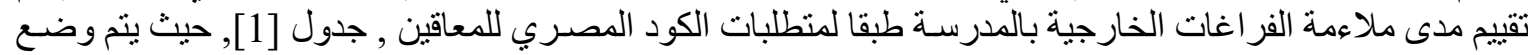

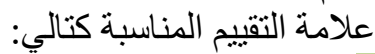

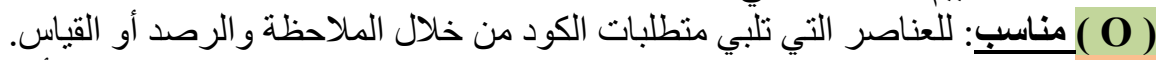

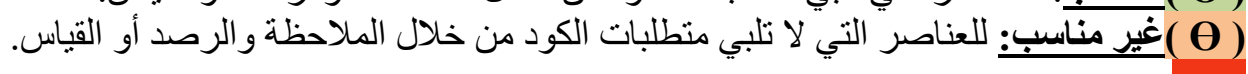

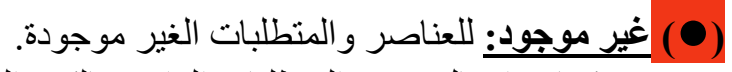

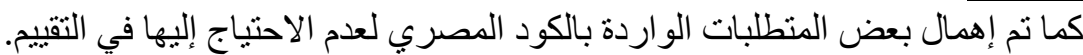

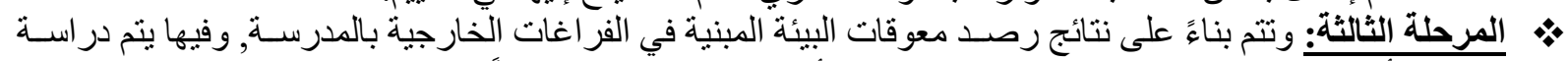

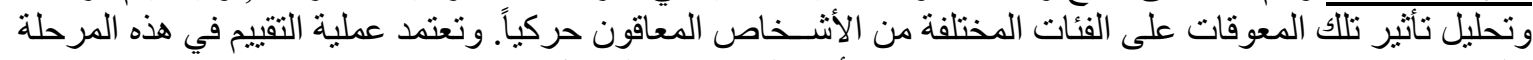

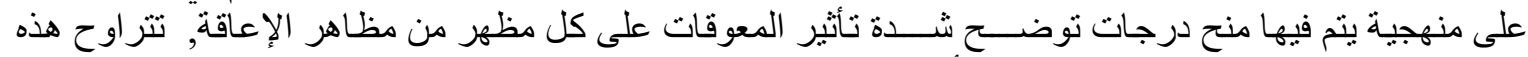

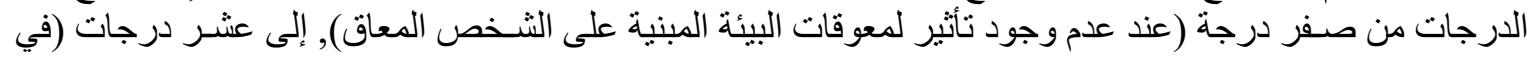

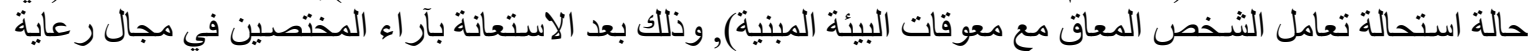

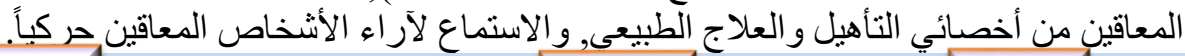

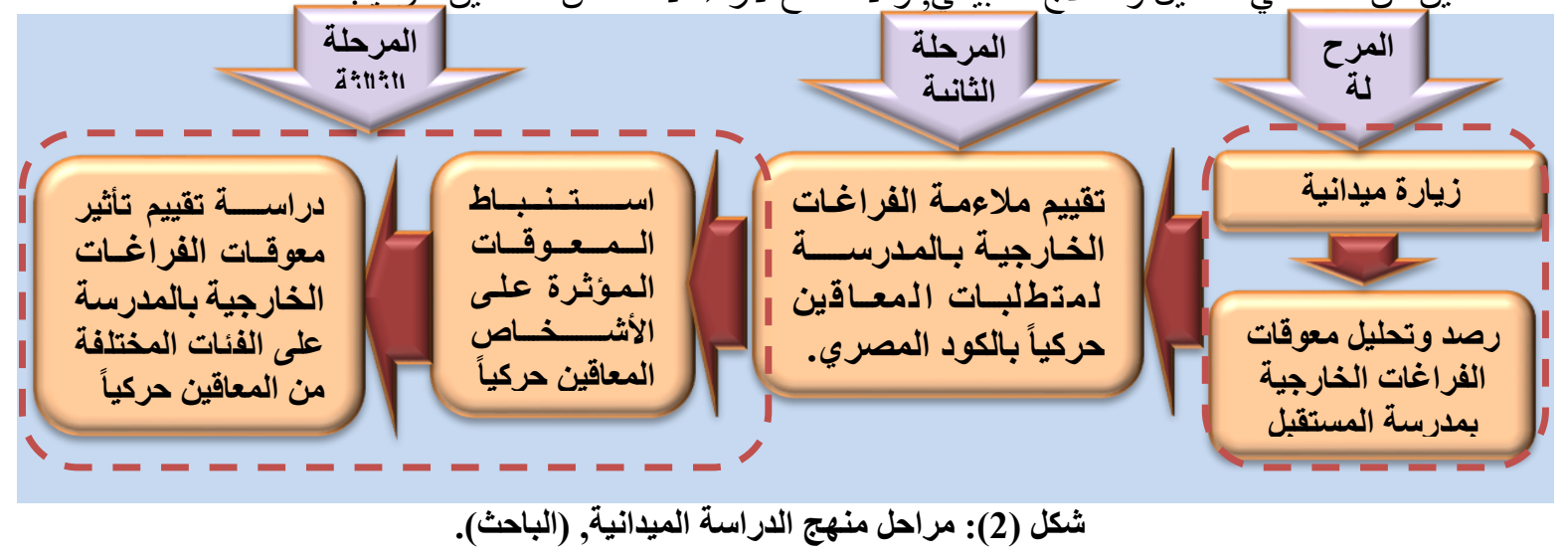


تقييم ملاءمة الفر اغات الخارجية بالمدارس التعليمية بمصر لذوى الإعاقة الحركية "دراسة حالة: مدرسة المستقبل الدولية بالأقصر"

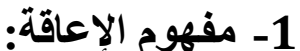

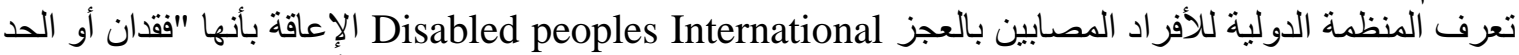

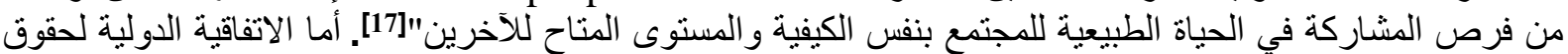

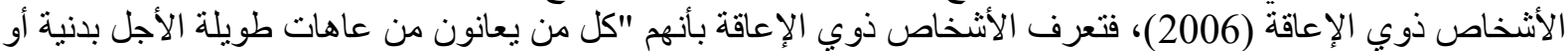

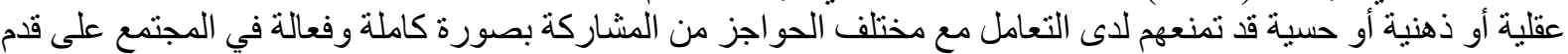

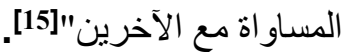

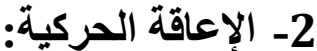

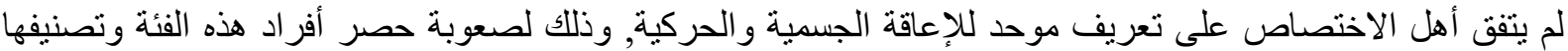

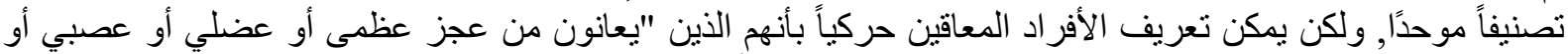

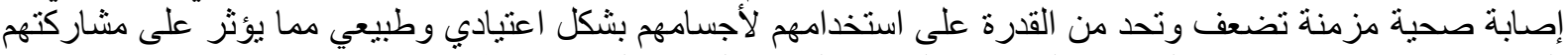

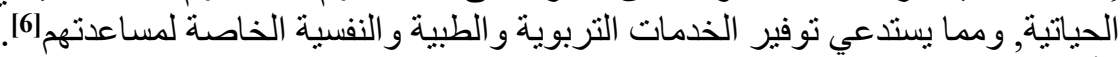

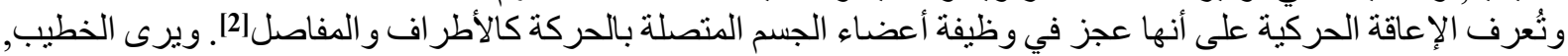

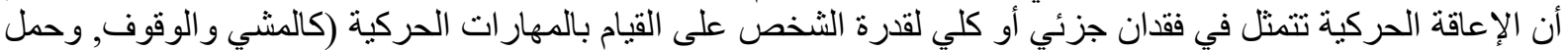

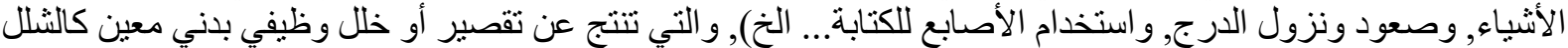

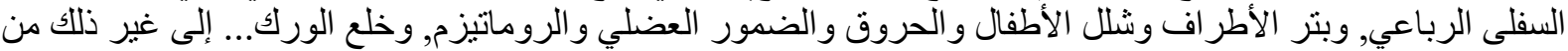

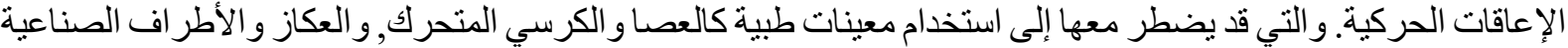

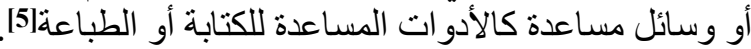

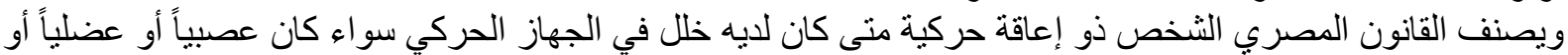

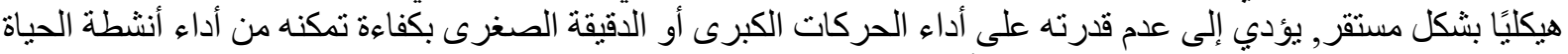

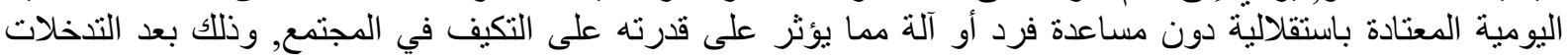

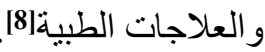

\section{-1-2 - تصنيفات الإعاقة الحركية:}

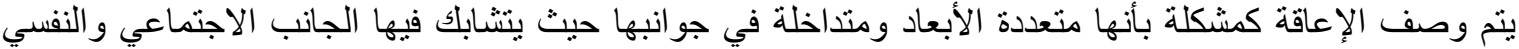

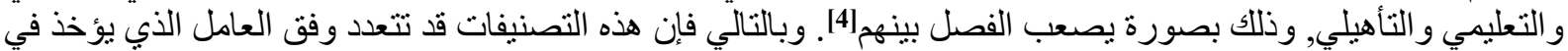

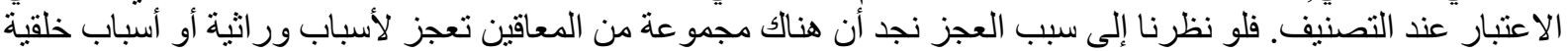

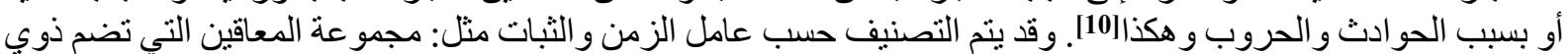

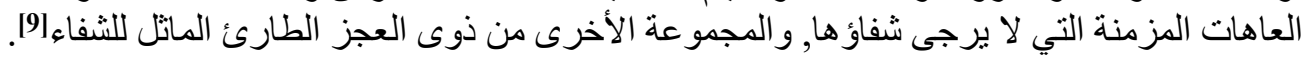

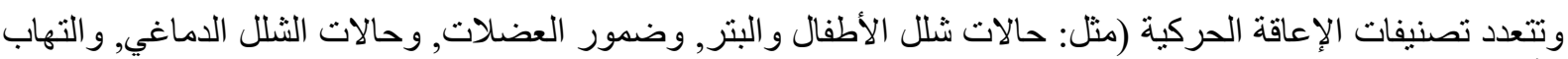

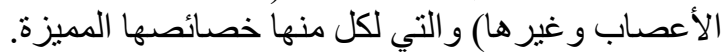

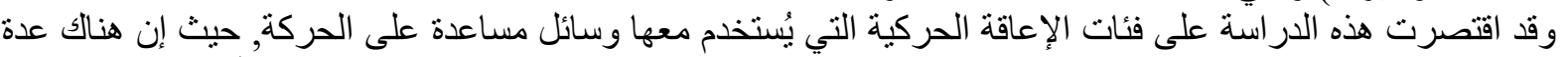

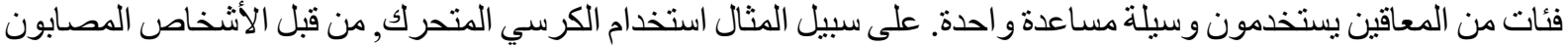

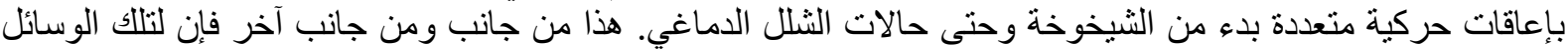

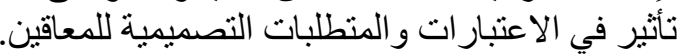

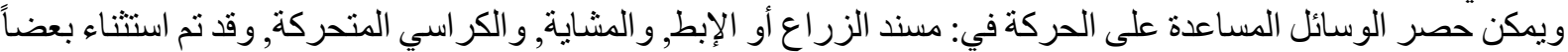

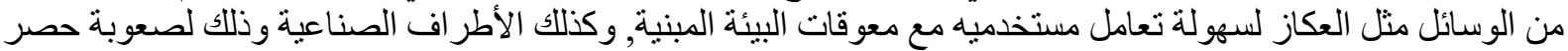

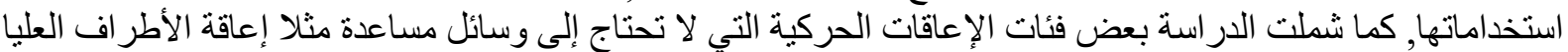
تجبيس أو بتر لتلك الأطر اف.

\section{2-2-2 - 2 مشكلات الإعاقة الحركية:}

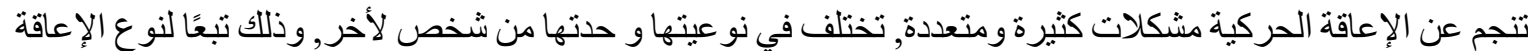

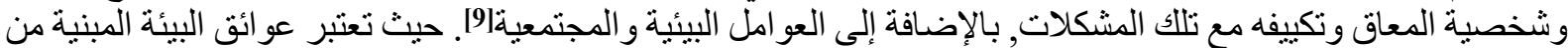
أكثر المشكلات تأثيرًا على الأشخاص الثعاقين.

-1-2-2 - 2 معوقات البيئة المبنية:

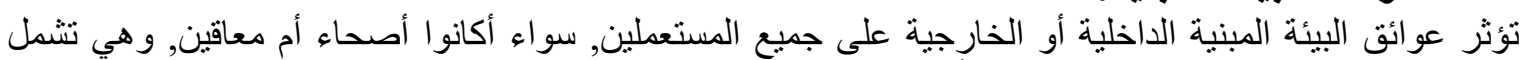

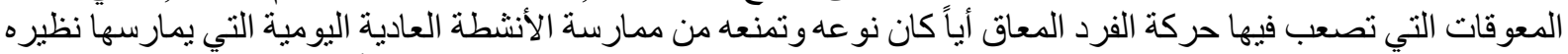

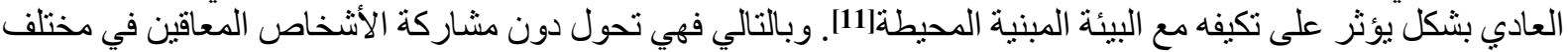

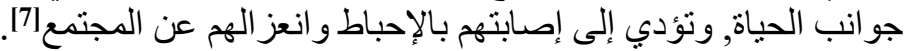




\section{3- التعريف بحالة الدراسة (مدرسة المستقبل الدولية بالأقصر):}

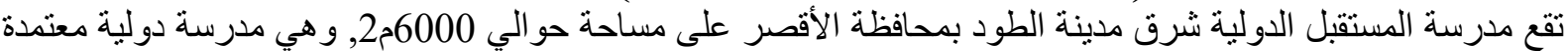

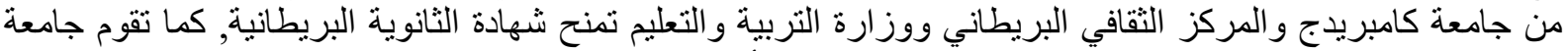

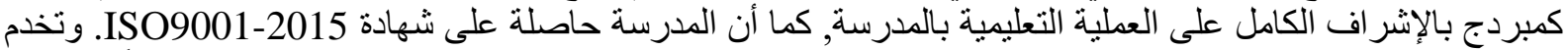

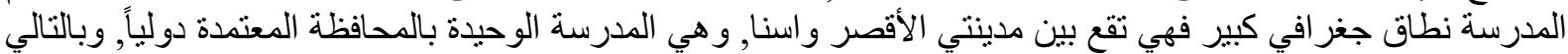

فهي مثال جيد كحالة در اسية.

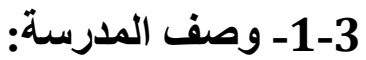

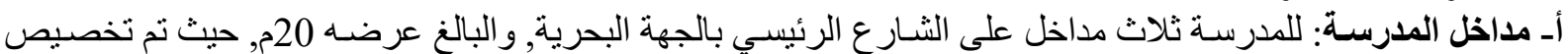

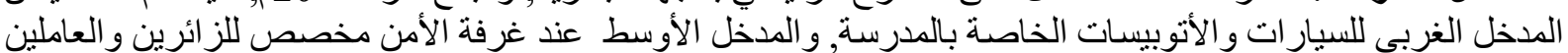

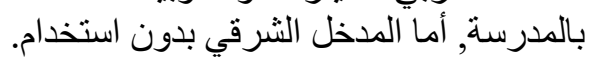
بـ الفراغات الخارجية: وتتكون من مو اقف سيار ات و اتو بيسات بالجهة الغربية, و ومناطق مظللة لألعاب الأطفال, و ولعبين

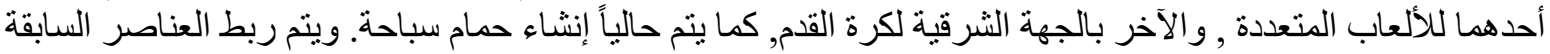

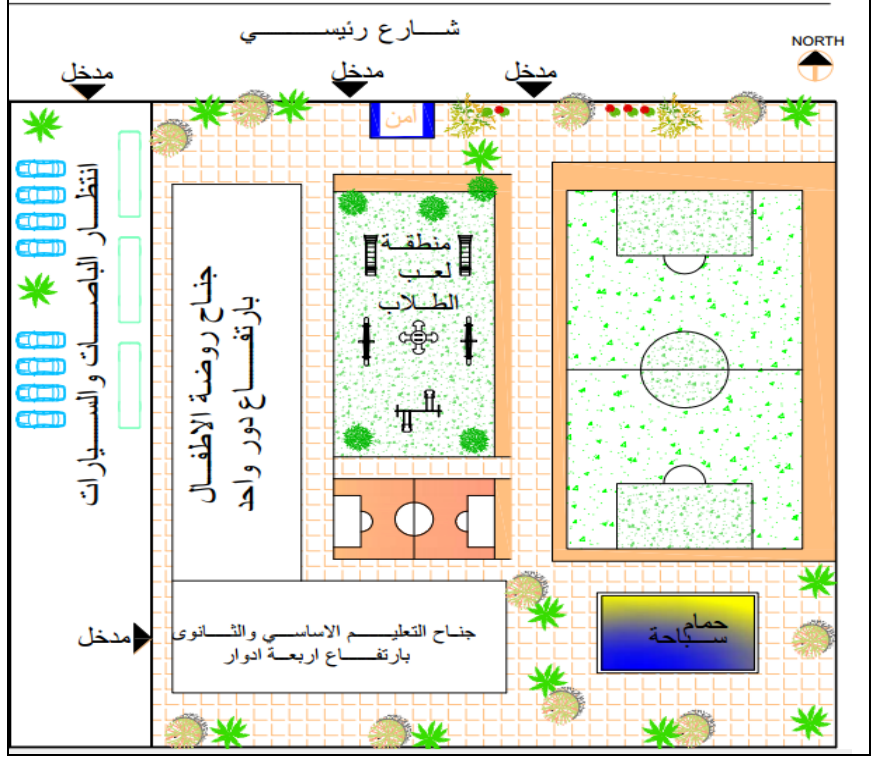

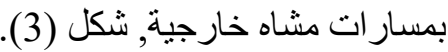

شكل (3): الموقع العام لمدرسة المستقبل الدولية, (الباحث)

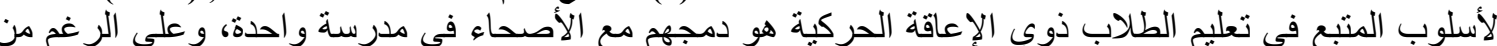

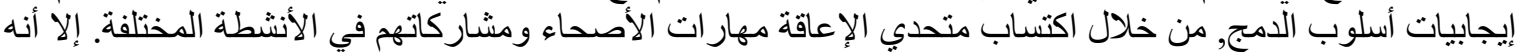

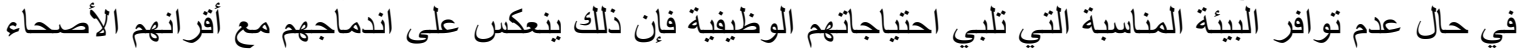

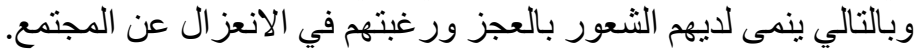

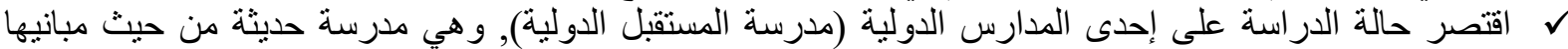

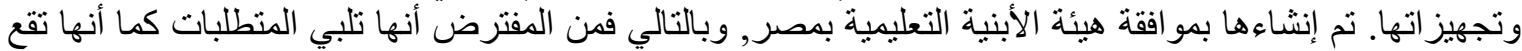

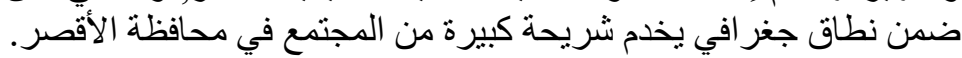

\section{4- تقييم ملاءمة الفراغات الخارجية بحالة الدراسة لذأوى الإعاقة الحركية:} 1-4-4 رصد وتحليل معوقات الفراغات الخارجية:

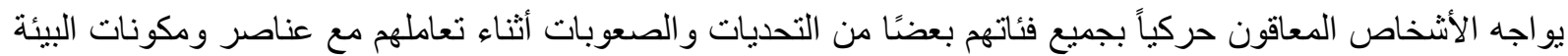
الخارجية بالمدرسة, وذللك بسبب عدم تلبية تللك العناصر للمتطلبات التصميمية المناسبة لهم والتي أقرتها ألها أكو اد المعاقين. و التي

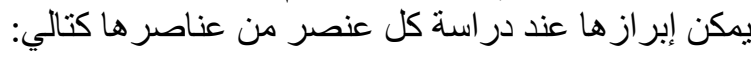

-1-1-4 - المسارات والطرقات الخارجية وملحقاتها:

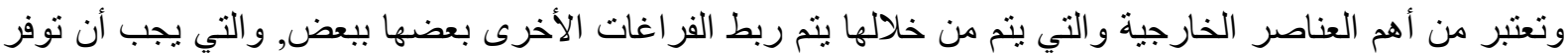

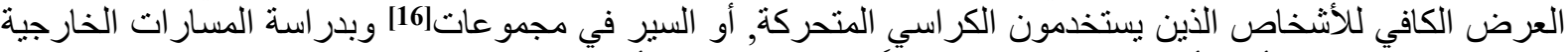

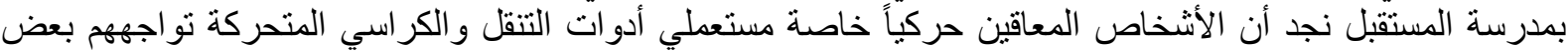

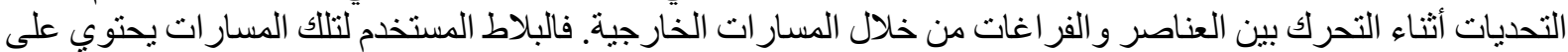


نتو وات و عناصر بارزة تُصعب من حركة الكراسي المتحركة, شكل (4). كما توجد بعض العور العوائق الدائمة كمشارب المياهر

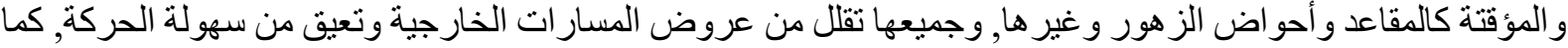

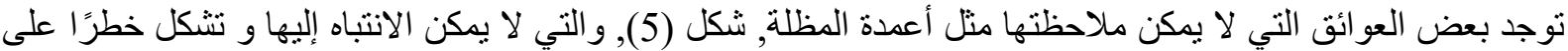

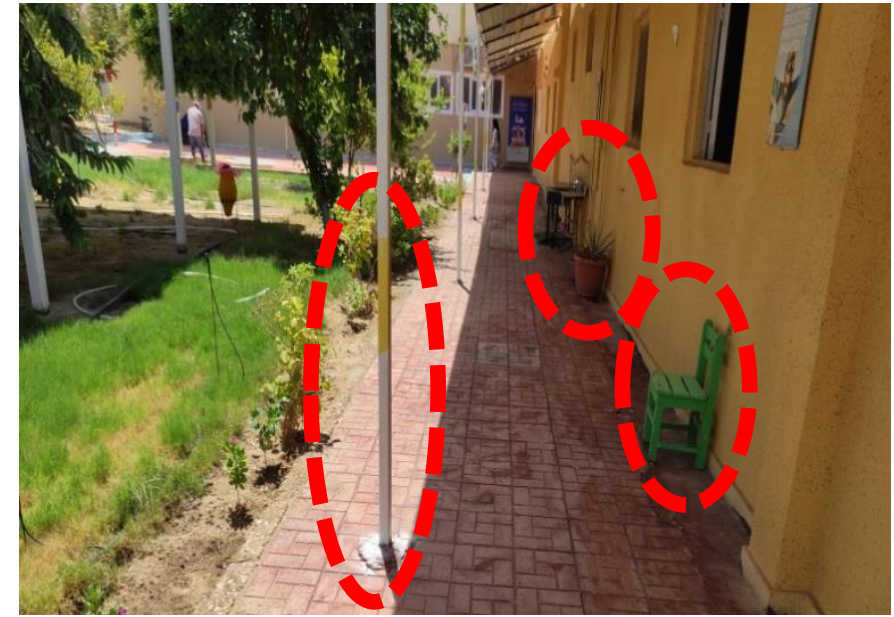

شكل (5): وجود عو ائق دائمة ومؤقتّة تعيق مسارات الحركة.

(تصوير الباحث).

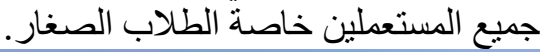

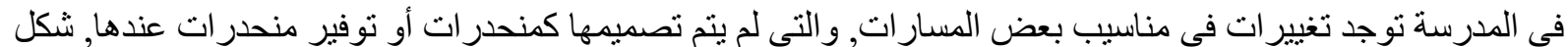

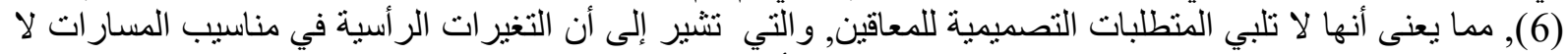

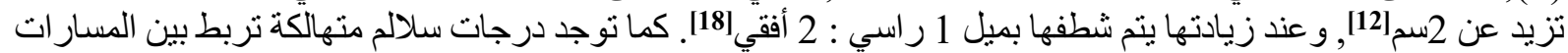
ذات المناسيب المختلفة, شكل (7). بالإضافة إلى أن تللك المسار ات غيل غير كافية لربط معظم الفر اغات الخارجية.

\section{2-1-4- منحدر صعود الأرصفة:}

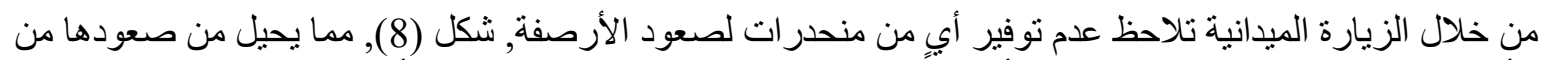

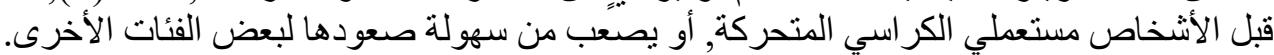

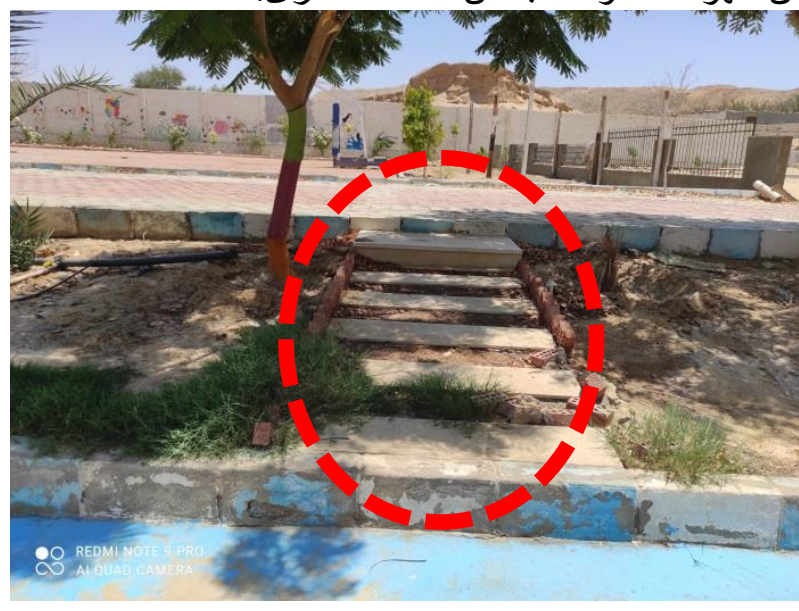

شكل (7): سلالم متهالكة تصعب من الوصول بين مسارات الحركة المختلفة, (تصوير الباحث).

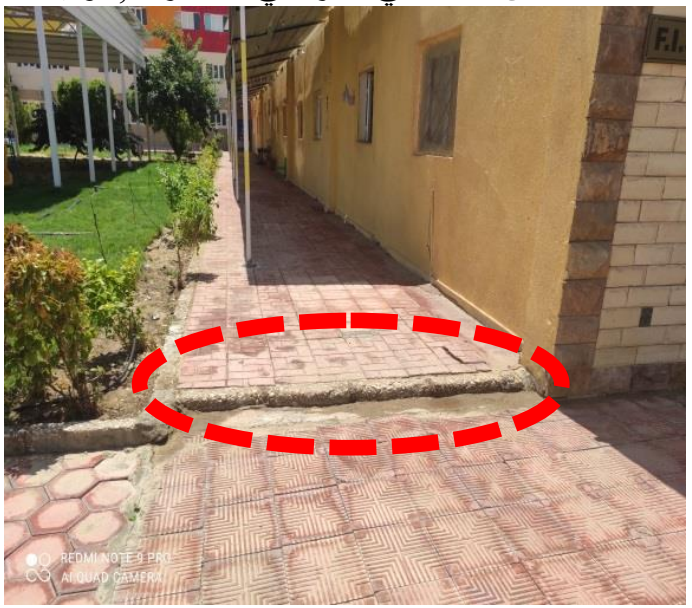

شكل (6): وجود فرق منسوب بين مسارات الحركة لم يتم تصميمها كمنحدر, (تصوير الباحث).

3-1-4 أماكن انتظار السيارات:

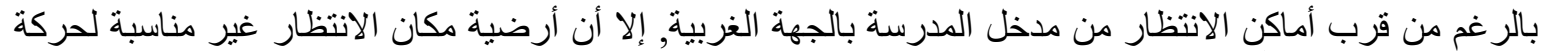

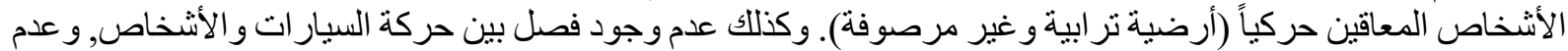

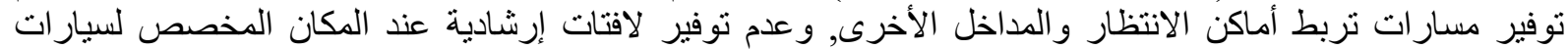

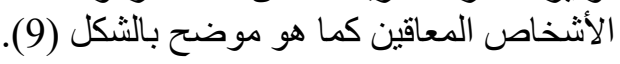




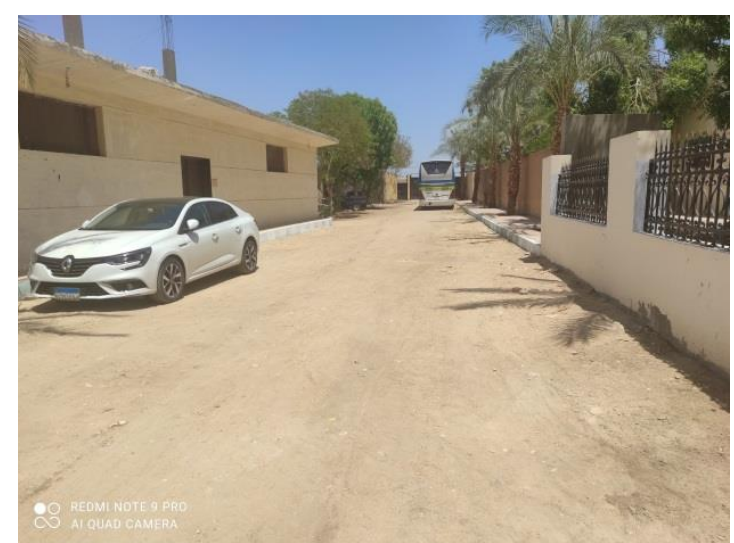

شكل (9):أماكن انتظار السيارات والباصات غير مرصوفة (باحة) ولا يتو افر بها أرصفة, (الباحث).

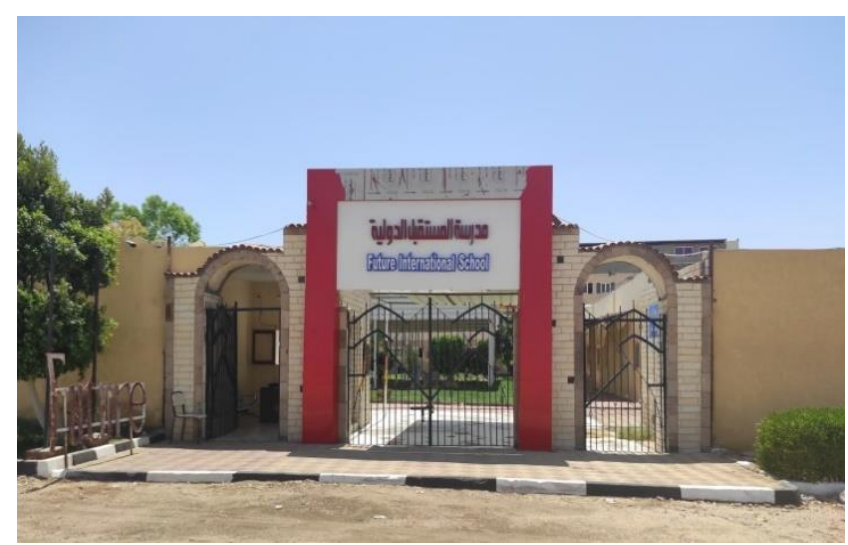

شكل (8): عدم توفير منحدر لصعود الرصيف أمام المدخل الرئيسي للمدرسة, (تصوير الباحث).

4-1-4 - 2-4 المقاعد الثابتة:

من الملاحظ عدم نوفير مقاعد للجلوس بالقدر الكافي في أغلب الفراغات الخارجية بالمدرسة, والمتاح منها تعيق مسارات الحركة, كما أن تللك المقاعد بأبعاد صغيرة و بالتالي فهي مخصصة للطلاب فقط و غير مناسبة لفئات كبار السن كما هو موضح بالثكل (5), السابق.

\section{-5-1-4- الساحات المفتوحة ومناطق اللعب:}

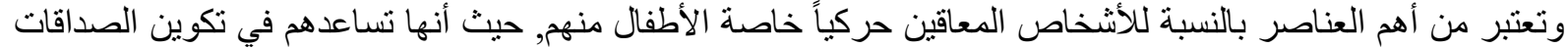

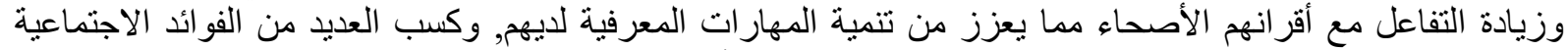

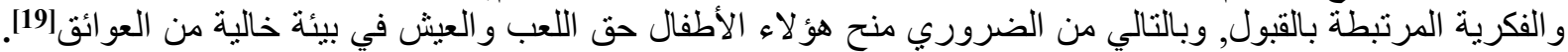

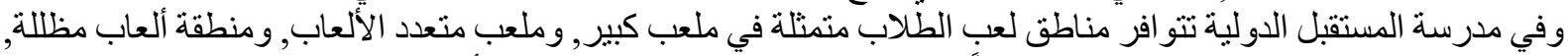

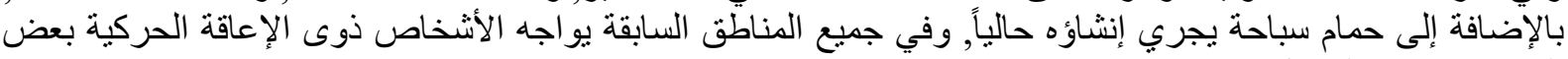

الصعوبات عند التعامل معها.

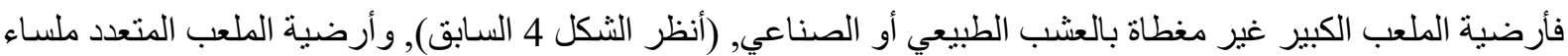

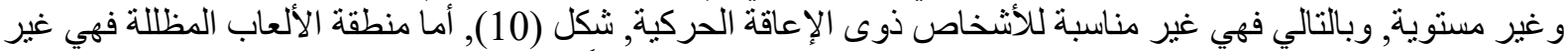

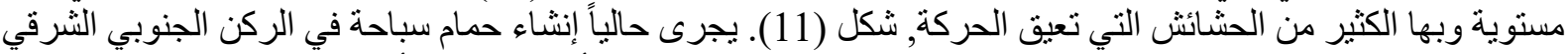

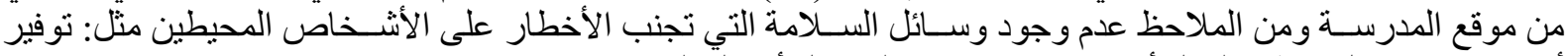

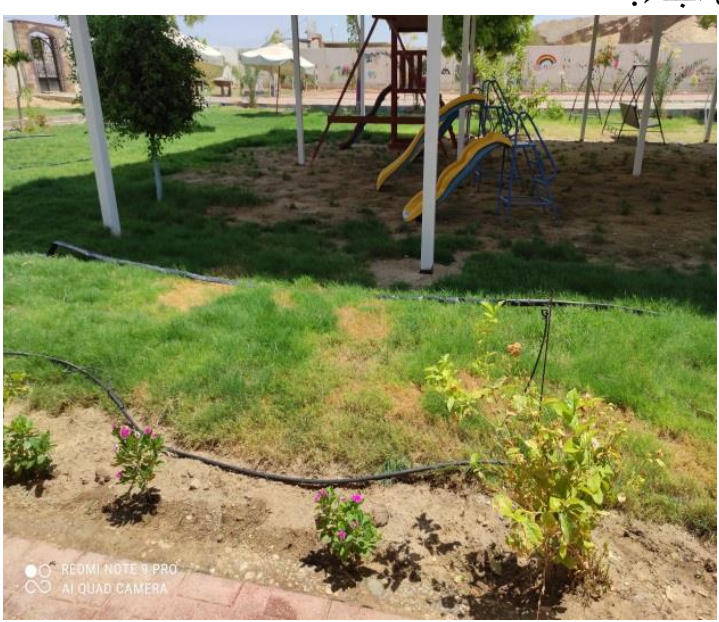

شكل (11): منطقة الألعاب المظلاة غير مستوية وبها الكثير من الحشائش, (تصوير الباحث).

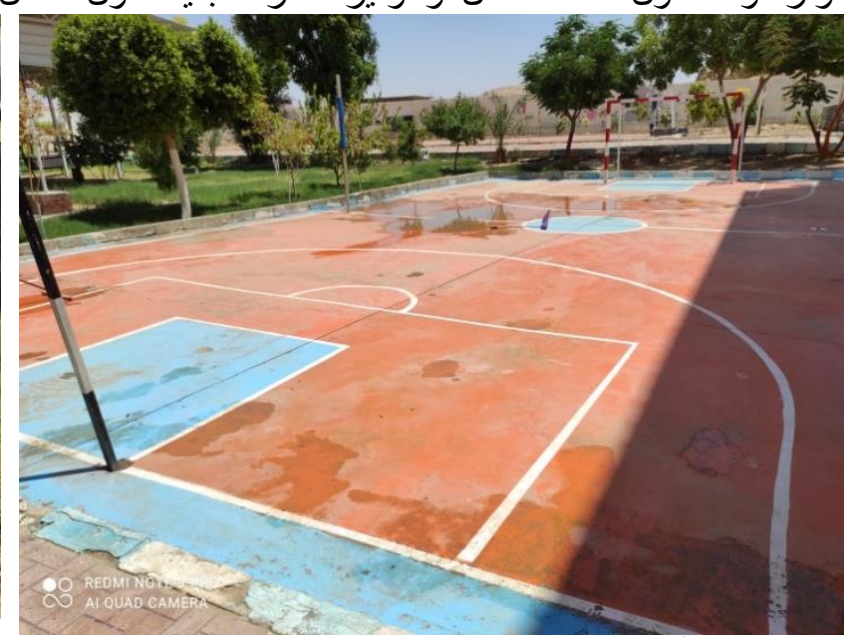

شكل (10): أرضية الملعب المتعدد ملساء وغير مستوية. (تصوير الباحث).

6-1-4- - المنحدرات الخارجية:

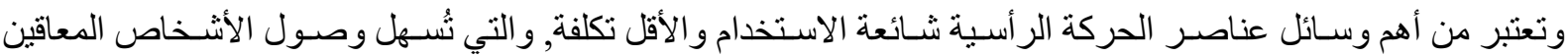

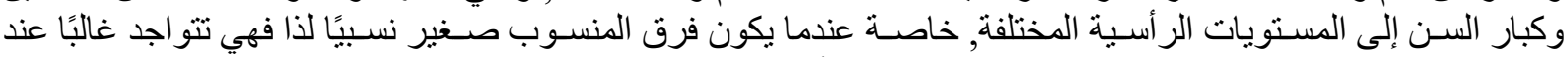

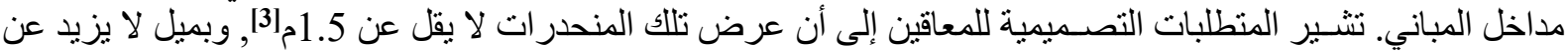




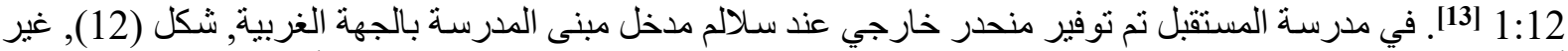

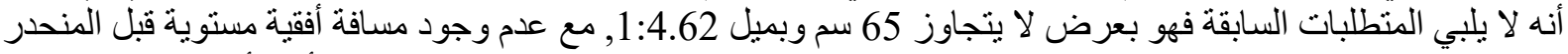

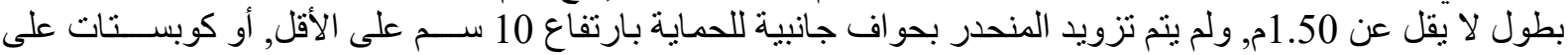
جانبيه.

\section{-7-1-4 السلالم الخارجية أمام المداخل:}

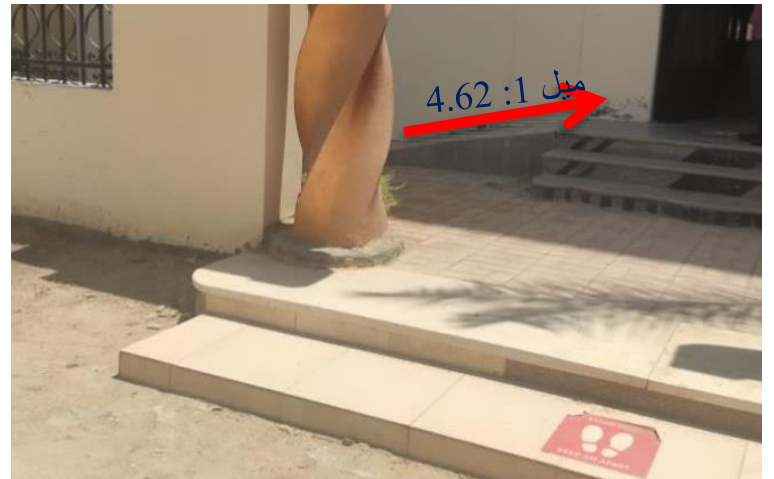

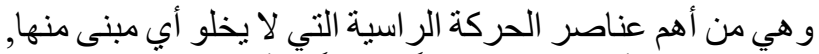

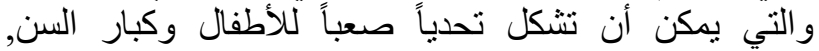

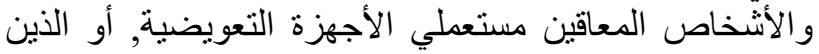

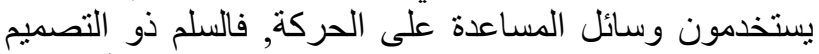

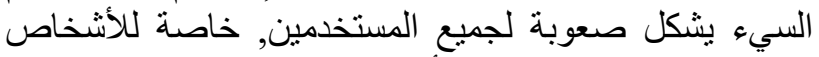

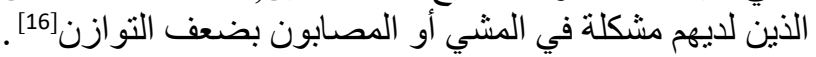

شكل (12): السلالم الخارجية والمنحدر عند المدخل الغربية بالمدرسة, (تصوير الباحث).

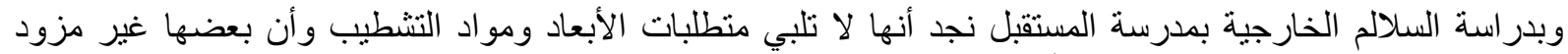

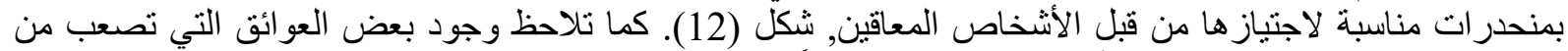

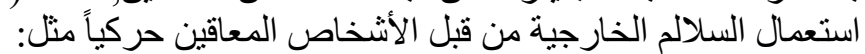

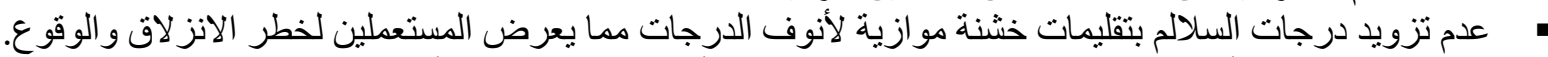

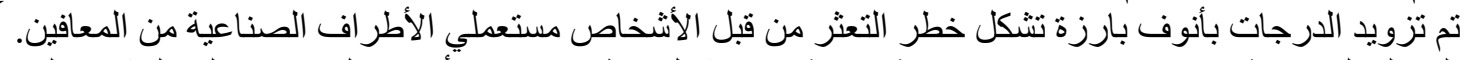

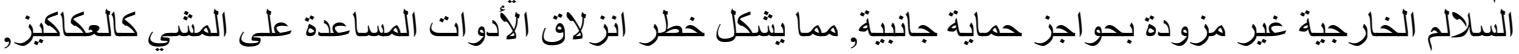
و المساند و غير ها. لم يتم توفير در ابزين للسلالم الخارجية

1-1-4 تقييم ملاعمة عناصر ومكونات الفراغات الخارجية بمدرسة المستقبل الاولية لمتطلبات الكود

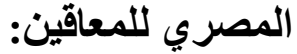

يتم من خلال الملاحظة واعتمادًا على أدو ات الدر اسة السابق ذكر ها تقييم مدى ملاءمة الفر اغات الخارجية بالمدرسة لمتطلبات

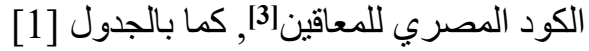
جدول [1]: تقييم عناصر ومكونات الفراغات الخارجية بالمدرسة لمنطلبات الكود المصري للمعاقين.

\begin{tabular}{|c|c|c|}
\hline 高 & المتطلبات الرئيسية والفرعية & 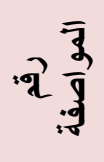 \\
\hline \multicolumn{3}{|c|}{ المسارات والطرقات الخارجية } \\
\hline$\Theta$ & أرضية المسارات مناسبة لحركة الكرسي المتحركة. & $1-1-2$ \\
\hline$\theta$ & عدم وجود عوائق في المسارات أو تقلل من عروض المسارات. & 2-1-2 \\
\hline$\theta$ & توفير مسار ات بديلة في حالة وجود عوائق مؤقتة كأعمال البناء & 8-1-2 \\
\hline $\mathrm{O}$ & توفير مسارات تخدم المعاقين حركيا تربط بين العناصر الخارجية مثل الفناء, الملاعب, أماكن الجلوس... الخ. & $2-2-6$ \\
\hline $\mathrm{O}$ & ون 2سم حواجز الأسطاية لا يقل ارتفاعها عن 10سم على جانبي المسار في حالة ارتفاع أرضية المسار أكثر & $1-1-2$ \\
\hline $\mathrm{O}$ & عرض المسار الرئيسي لا يقل عن 1.80م, الثانوي عن 1.50م. & 2-1-2 \\
\hline $\mathrm{O}$ & سطح غرف التفتيش أو الأمطار في مستوى المسار أو خارج حدود المسار. & $7-1-2$ \\
\hline$\theta$ & عمل حواجز حماية لمناطق العمل أو الحفر أو الأماكن التي تثكل خطراً على المعاقين. & 8-1-2 \\
\hline $\mathrm{O}$ & ميل المسار لا يزيد عن 1: 20 وفي حالة زيادة فإنه يتم تصميمه كمنحدر. & \multirow{2}{*}{ 3-1-2 } \\
\hline $\mathrm{O}$ & الميل العرضي للمسار لا يزيد عن 1: 50. & \\
\hline
\end{tabular}




\begin{tabular}{|c|c|c|}
\hline $\mathrm{O}$ & | ارتفاع بردورة الرصيف لا تزيد عن 15سم. & 4-1-2 \\
\hline \multicolumn{3}{|c|}{ ن نحدر صعود الأرصفة } \\
\hline$\bullet$ & توفيرها عند ناصية عبور المشاة و أمام مداخل المباني وعند مناطق انتظار السيارات. & \multirow{2}{*}{ 6-1-2 } \\
\hline$\bullet$ & لا يقل العرض الصافي لها عن متر. & \\
\hline \multicolumn{3}{|c|}{ 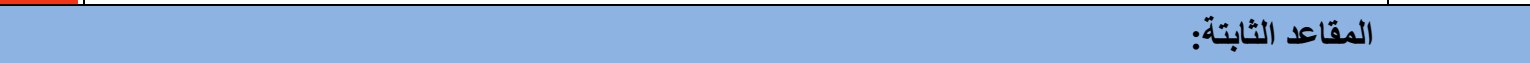 } \\
\hline $\mathrm{O}$ & وجود مساحة بجوار المقعد المخصص للمعاقين للكرسي المتحرك بأبعاد 140× 90 سم على الأقل. & 1-3-3 \\
\hline$\bullet$ & المسافات بين الكراسي الثابتة يسمح بحركة الكرسي المتحرك ( 90 سم على الأقّل). & 1-3-3 \\
\hline \multicolumn{3}{|c|}{ الساحات المفتوحة والملاعب: } \\
\hline $\mathrm{O}$ & توفير إمكانية الوصول إلى أماكن جلوس المعاقين & 3-8-6 \\
\hline$\bullet$ & إتاحة 1\% على الأقل من مقاعد الجلوس مهيأة لاستخدام المعاقين حركيا. & 3-8-6 \\
\hline$\bullet$ & توزيع مقاعد جلوس المعاقين على المناطق المختلفة من الموقع و عند أماكن الجلوس وصالات الألعاب. & 3-8-6 \\
\hline \multicolumn{3}{|c|}{ 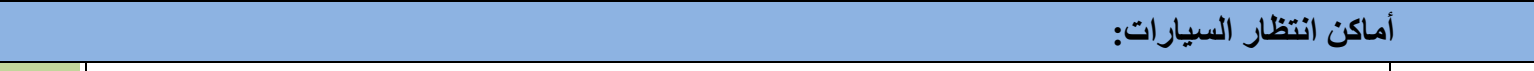 } \\
\hline $\mathrm{O}$ & توفير أماكن مخصصة لسيار ات المعاقين بعرض لا يقل عن 3.60م. & 3-3-2 \\
\hline $\mathrm{O}$ & أماكن انتظار السيارات تكون أقرب ما يكون من المداخل الرئيسية. & 1-3-2 \\
\hline$\bullet$ & توفير مسار بنفس الثروط السابقة يربط أماكن الانتظار والمداخل الرئيسية. & 2-4-2 \\
\hline $\mathrm{O}$ & توفير الحد الأدنى من أماكن الانتظار المخصصة للأشخاص المعاقين. & 2-3-2 \\
\hline $\mathrm{O}$ & المسافة بين أماكن الانتظار والمدخل لا تزيد عن 50متر & 3-3-2 \\
\hline$\bullet$ & المسار بين مكان الانتظار ومنحدر صعود الأرصفة لا يقل عرضه عن 1.20م. & 3-3-2 \\
\hline$\bullet$ & وجود حاجز بين مكان وقوف السيارة ومسار الحركة في حالة عدم وجود رصيف. & 4-3-2 \\
\hline$\bullet$ & توفير لافتة تحدد مكان الانتظار المخصص لسيارات المعاقين. & 5-3-2 \\
\hline$\bullet$ & وجود علامة الرمز الدولي للإعاقة على المكان المخصص لسيارات المعاقين. & 1-3-1-3 \\
\hline$\bullet$ & توفير لافتة عند المكان المخصص على الحائط أو على قائم. & 1-3-1-3 \\
\hline$\bullet$ & اللافتة المثبتة علي قائم تكون على ارتفاع 1.5: 2م من منتصفها. & 1-3-1-3 \\
\hline \multicolumn{3}{|c|}{ المندرات الخارجية. } \\
\hline$\bullet$ & يتم توفيرها عند السلالم أو عند التغير في مستوى المسار. & 1-2-2 \\
\hline$\Theta$ & ميل المنحدر لا يزيد عن 1: 12. & $1-2-2$ \\
\hline $\mathrm{O}$ & مواد أرضية المنحدر خشنة الملمس مانعة للانزلاق. & 2-2-2 \\
\hline$\Theta$ & عرض المنحدر لا يقل عن 1.5م. & \multirow{2}{*}{$3-2-2$} \\
\hline$\Theta$ & وجود مسافة أفقية مستوية قبل وبعد المندر بطول لا يقل عن 1.50م & \\
\hline$\bullet$ & تزويد المنحدر بحواف جانبية للحماية بارتفاع 10 سم علي الأقل. & $4-2-2$ \\
\hline$\bullet$ & تزويد المنحدر بكوبستات على الجانبين وبكامل طول المنحدر تمتـ مسافة 30 سم قبل وبعد نهاية المنحدر. & $5-2-2$ \\
\hline$\bullet$ & | الكوبستات تكون على ارتفاع 80 سم. & $5-2-2$ \\
\hline \multicolumn{3}{|c|}{ السلالم الخارجية. } \\
\hline$\bullet$ & تزويد الدرجات بتقليمات خثنة موازية لأنوف الدرجات لمنع الانزلاق. & $1-6-2$ \\
\hline $\mathrm{O}$ & | ارتفاع القائمة بين 15 : 17 سم, وعمق النائمة بين 27: 30سم. & 2-6-2 \\
\hline $\mathrm{O}$ & العرض الصافي للارج لا يقل عن 1.30م. & 2-6-2 \\
\hline$\theta$ & مراعاة عدم وجود أنوف بارزة للارجات ويفضل ميل القائم للاخل بمقدار بين 2 : 3سم. & $2-6-2$ \\
\hline$\theta$ & مراعاة وجود حواف جانبية للسلالم التي لا تحيط بها حوائط. & $3-6-2$ \\
\hline
\end{tabular}


تقييم ملاءمة الفر اغات الخارجية بالمدارس التعليمية بمصر لذوى الإعاقة الحركية "دراسة حالة: مدرسة المستقبل الدولية بالأقصر"

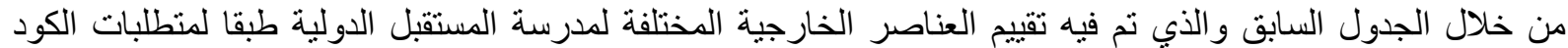
المصري للمعاقين. يتم في الجدول [2] التالي توضيح إجمالي الدرجات والنسب المبن المئوية لمدى تلبية العناصر الخارجية

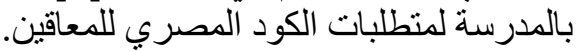

جدول[2]: يوضح إجمالي الدرجات والنسب المئوية لمدى تلبية العناصر الخارجية بالمدرسة لمتطلبات الكود المصري للمعاقين.

\begin{tabular}{|c|c|c|c|c|c|c|c|c|}
\hline \multicolumn{6}{|c|}{ علامات التقييم } & \multirow{3}{*}{ عدد المتطلبات } & \multirow{3}{*}{ المسارات والطرقات الخارجية } & \multirow{3}{*}{$\begin{array}{l}0 \\
1\end{array}$} \\
\hline \multicolumn{2}{|c|}{ غير موجود } & \multicolumn{2}{|c|}{ غير مناسب } & \multicolumn{2}{|c|}{ 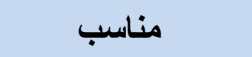 } & & & \\
\hline$\% 0.0$ & $\mathbf{0}$ & $\% 36.4$ & 4 & $\% 63.6$ & 7 & & & \\
\hline$\% 100.0$ & 2 & $\% 0.0$ & $\mathbf{0}$ & $\% 0.0$ & $\mathbf{0}$ & 2 & منحدر صعود الأرصفة. & 2 \\
\hline$\% 50.0$ & 1 & $\% 0.0$ & $\mathbf{0}$ & $\% 50.0$ & 1 & 2 & المقاعد الثابتة. & 3 \\
\hline$\% 66.7$ & 2 & $\% 0.0$ & $\mathbf{0}$ & $\% 33.3$ & 1 & 3 & الساحات المفتوحة والملاعب. & 4 \\
\hline$\% 63.6$ & 7 & $\% 0.0$ & $\mathbf{0}$ & $\% 36.4$ & 4 & 11 & أماكن انتظار السيارات. & 5 \\
\hline$\% 50.0$ & 4 & $\% 37.5$ & 3 & $\% 12.5$ & 1 & 8 & المنحدرات الخارجية. & 6 \\
\hline$\% 50.0$ & 1 & $\% 0.0$ & $\mathbf{0}$ & $\% 50.0$ & 1 & 2 & السلالم الخارجية. & 7 \\
\hline$\% 44$ & 17 & $\% 18$ & 7 & $\% 38$ & 15 & 39 & المجموع & \\
\hline
\end{tabular}

القيم الصغرى لتلبية المتطلبات.

القيم العظمى لتلبية المتطلبات.

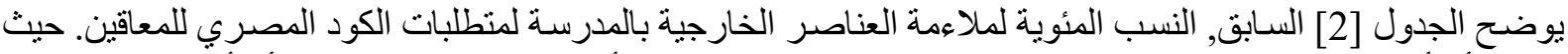

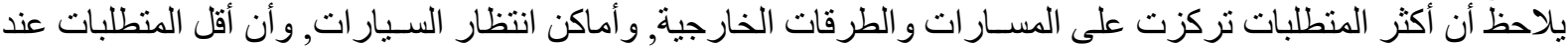

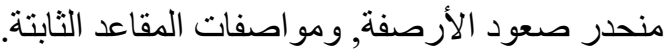

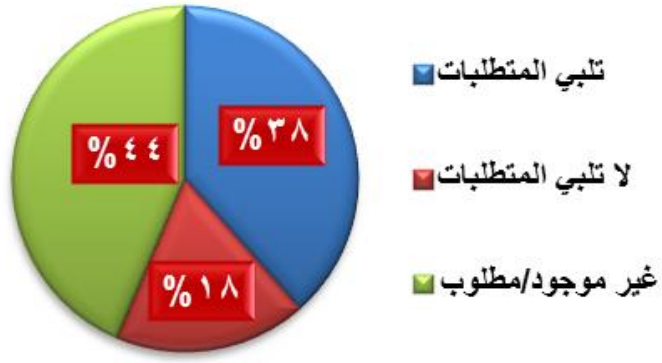

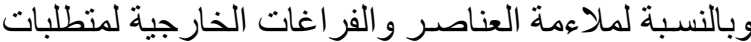

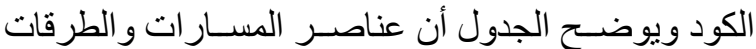

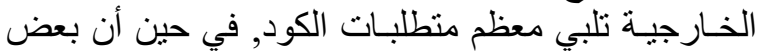

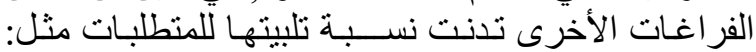

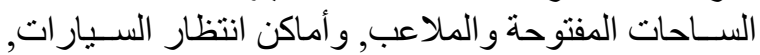

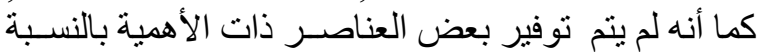

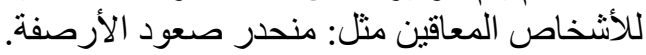

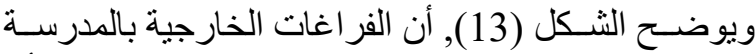

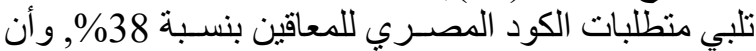

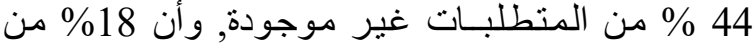

شكل (13): يوضح مدى ملاعمة الفراغات الخارجية بمدرسة المتطلبات موجودة و لأنها غير مطابقة لمتطلبات الكود. المستقبل الدولية لمتطلبات الكود المصري للمعاقين.

ك-4-4 دراسة تأثير معوقات البيئة الخارجية بمدرسة المستقبل الدولية على المظاهر المختلفة من الإعاقة الحركية: كما بالجدول [3 [3 التالي.

جدول[3]: يوضح تأثير معوقات البيئة الذارجية بمدرسة المستقبل على المظاهر المختلفة من الإعاقة الحركية.

\begin{tabular}{|c|c|c|c|c|c|c|c|c|c|c|c|c|}
\hline \multirow{4}{*}{$\begin{array}{l}\bar{z} \\
\text { s. }\end{array}$} & \multicolumn{10}{|c|}{ مظاهر الإعاقة الحركية: } & \multirow{4}{*}{ معوقات البيئة المبنية } & \\
\hline & \multicolumn{6}{|c|}{ الاعتماد على وسائل مساعدة على الحركة } & \multicolumn{4}{|c|}{ إصابة أو بتر لإحدي } & & \\
\hline & \multicolumn{2}{|c|}{ كتحرتئ } & \multicolumn{2}{|c|}{ مثاية } & \multicolumn{2}{|c|}{ مسند ذراع أو } & \multicolumn{2}{|c|}{ 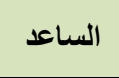 } & \multicolumn{2}{|c|}{ اليا } & & s \\
\hline & 哥 & 包 & ?.?.3. & 量 & 露 & 弯 & 哥 & 或 & 弱: & 㢤 & & \\
\hline & & & & & & & & & & & الطرقات الذارجية وملحقاتها. & \\
\hline
\end{tabular}




\begin{tabular}{|c|c|c|c|c|c|c|c|c|c|c|c|c|}
\hline 34 & 5 & 7 & 3 & 5 & 6 & 8 & 0 & 0 & 0 & 0 & نتؤات وعناصر بأرزة. & 1 \\
\hline 29 & 7 & 6 & 5 & 4 & 4 & 3 & 0 & 0 & 0 & 0 & وجود عوائق تقلل من عرض المسارات & 2 \\
\hline 33 & 8 & 9 & 4 & 5 & 3 & 4 & 0 & 0 & 0 & 0 & توجد تغييرات في مناسيب بعض المسارات & 3 \\
\hline 51 & $\begin{array}{l}1 \\
0\end{array}$ & 10 & 8 & 9 & 8 & 6 & 0 & 0 & 0 & 0 & والمسارد درجات ذات المناسيب متهاكة تربطة بين & 4 \\
\hline 47 & $\begin{array}{l}1 \\
0\end{array}$ & 10 & 6 & 6 & 7 & 8 & 0 & 0 & 0 & 0 & ارتفاع بعض الأرصفة أكثر من 15 سم & 5 \\
\hline 47 & $\begin{array}{l}1 \\
0\end{array}$ & 10 & 6 & 6 & 7 & 8 & 0 & 0 & 0 & 0 & عدم توفير منحدر صعود الأرصفة. & 6 \\
\hline $\begin{array}{c}24 \\
1\end{array}$ & $\begin{array}{l}5 \\
0\end{array}$ & 52 & 32 & 35 & 35 & 37 & 0 & 0 & 0 & 0 & \multicolumn{2}{|l|}{ 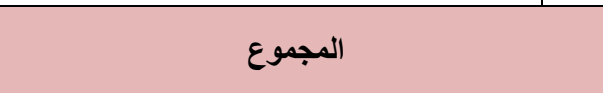 } \\
\hline & & & & & & & & & & & \multicolumn{2}{|l|}{ بـ أماكن انتظار السيارات } \\
\hline 38 & 6 & 7 & 5 & 7 & 6 & 7 & 0 & 0 & 0 & 0 & بعد أماكن الاتظظار من بعض المداخل & 1 \\
\hline 34 & 5 & 7 & 3 & 5 & 6 & 8 & 0 & 0 & 0 & 0 & أرضية مكان الانتظار ( ترابية وغير مرصوفة). & 2 \\
\hline 44 & 7 & 8 & 6 & 8 & 7 & 8 & 0 & 0 & 0 & 0 & و عدماخلوفير مسارات تربيط أماكن الانتظار & 3 \\
\hline $\begin{array}{c}11 \\
6\end{array}$ & $\begin{array}{l}1 \\
8\end{array}$ & 22 & 14 & 20 & 19 & 23 & 0 & 0 & 0 & 0 & \multicolumn{2}{|l|}{ 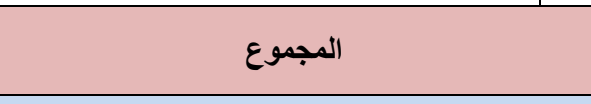 } \\
\hline & & & & & & & & & & & \multicolumn{2}{|l|}{ ج- المقاعد الثابتة } \\
\hline 32 & 0 & 0 & 6 & 4 & 7 & 5 & 3 & 2 & 3 & 2 & عدم توفيرها بالقدر الكافي في المسارات. & 1 \\
\hline & & & & & & & & & & & \multicolumn{2}{|l|}{ دـ الساحات المفتوحة ومناطق اللعب } \\
\hline 34 & 5 & 7 & 3 & 5 & 6 & 8 & 0 & 0 & 0 & 0 & أرضية الملعب الكبير ترابية. & 1 \\
\hline 30 & 2 & 2 & 6 & 5 & 7 & 8 & 0 & 0 & 0 & 0 & أرضيات الملعب المتعدد ملساء وغير مستوية & 2 \\
\hline 34 & 6 & 8 & 4 & 4 & 5 & 7 & 0 & 0 & 0 & 0 & الكثير من الألعاب المظلة فهي غير مستوية وبها & 3 \\
\hline 98 & $\begin{array}{l}1 \\
3\end{array}$ & 17 & 13 & 14 & 18 & 23 & 0 & 0 & 0 & 0 & 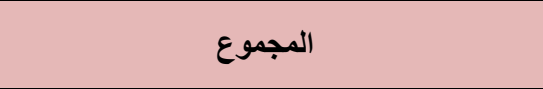 & \\
\hline & & & & & & & & & & & \multicolumn{2}{|l|}{ هـ ـ المنحدرات } \\
\hline 31 & 9 & 7 & 6 & 3 & 4 & 2 & 0 & 0 & 0 & 0 & عرض المنحدر لا يتجاوز 65 سم & 1 \\
\hline 36 & 6 & 9 & 6 & 3 & 7 & 5 & 0 & 0 & 0 & 0 & شدة اندار ميول المنحدرات & 2 \\
\hline 30 & 3 & 3 & 4 & 4 & 8 & 8 & 0 & 0 & 0 & 0 & عدم تزويد المنحدر بحواف جانبية للحماية & 3 \\
\hline 42 & 7 & 7 & 8 & 8 & 6 & 6 & 0 & 0 & 0 & 0 & عدم تزويد المنحدر بدرابزين على الجانبين & 4 \\
\hline 72 & $\begin{array}{l}1 \\
0\end{array}$ & 10 & 6 & 6 & 10 & 10 & 5 & 5 & 5 & 5 & ألانزضية بعض المنحدرات ملساء تساعد على & 5 \\
\hline $\begin{array}{c}21 \\
1\end{array}$ & $\begin{array}{l}3 \\
5 \\
\end{array}$ & 36 & 30 & 24 & 35 & 31 & 5 & 5 & 5 & 5 & \multicolumn{2}{|l|}{ ل } \\
\hline & & & & & & & & & & & \multicolumn{2}{|l|}{ و - السلالم الخارجية. } \\
\hline 32 & $\begin{array}{l}1 \\
0 \\
\end{array}$ & 10 & 2 & 3 & 3 & 4 & 0 & 0 & 0 & 0 & عدم تزويد درجات السلالم بتقليمات خشنة & 1 \\
\hline 53 & $\begin{array}{l}1 \\
0 \\
\end{array}$ & 10 & 4 & 8 & 5 & 8 & 0 & 4 & 0 & 4 & ارتفاع قوائم السلالم الخارجية & 2 \\
\hline 44 & $\begin{array}{l}1 \\
0 \\
\end{array}$ & 10 & 4 & 4 & 8 & 8 & 0 & 0 & 0 & 0 & الحواف الجانبية غير مزودة بحواجز حماية. & 3 \\
\hline 48 & $\begin{array}{l}1 \\
0 \\
\end{array}$ & 10 & 8 & 8 & 6 & 6 & 0 & 0 & 0 & 0 & الارابزين غير متوفر على جانبي السلم & 4 \\
\hline $\begin{array}{c}17 \\
7 \\
\end{array}$ & $\begin{array}{l}4 \\
0 \\
\end{array}$ & 40 & 18 & 23 & 22 & 26 & 0 & 4 & 0 & 4 & \multicolumn{2}{|l|}{ 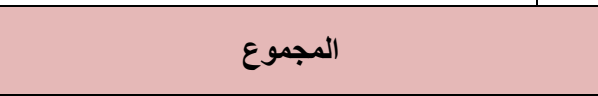 } \\
\hline
\end{tabular}




\begin{tabular}{|c|c|c|c|c|c|c|c|c|c|c|c|}
\hline$\underset{\infty}{\stackrel{n}{\infty}}$ & 욤 & $\widehat{0}$ & $\stackrel{m}{F}$ & 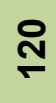 & $\stackrel{m}{\sim}$ & $\stackrel{10}{+}$ & $\infty$ & $\mp$ & $\infty$ & $\mp$ & المجموع الكلي لجميع العناصر. \\
\hline
\end{tabular}

يتضح لنا من خلال الجدول [3], السابق أن فئات الأشخاص المعاقون بإصابات أو بتر للأطر اف العلبا لا تؤثر عليهم المعوقات الإقات

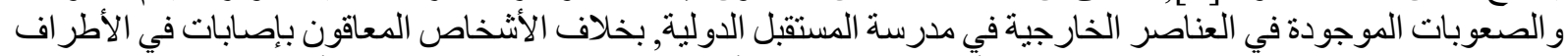

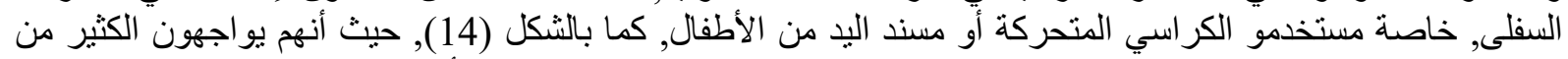

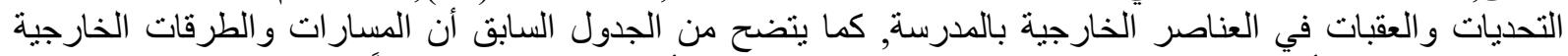

بالمدرسة توجد بها أكثر المعوقات والصعوبات التئة التي تؤثر على فئات الأشخاص المعاقين حركياً, كما بالثكل (15).

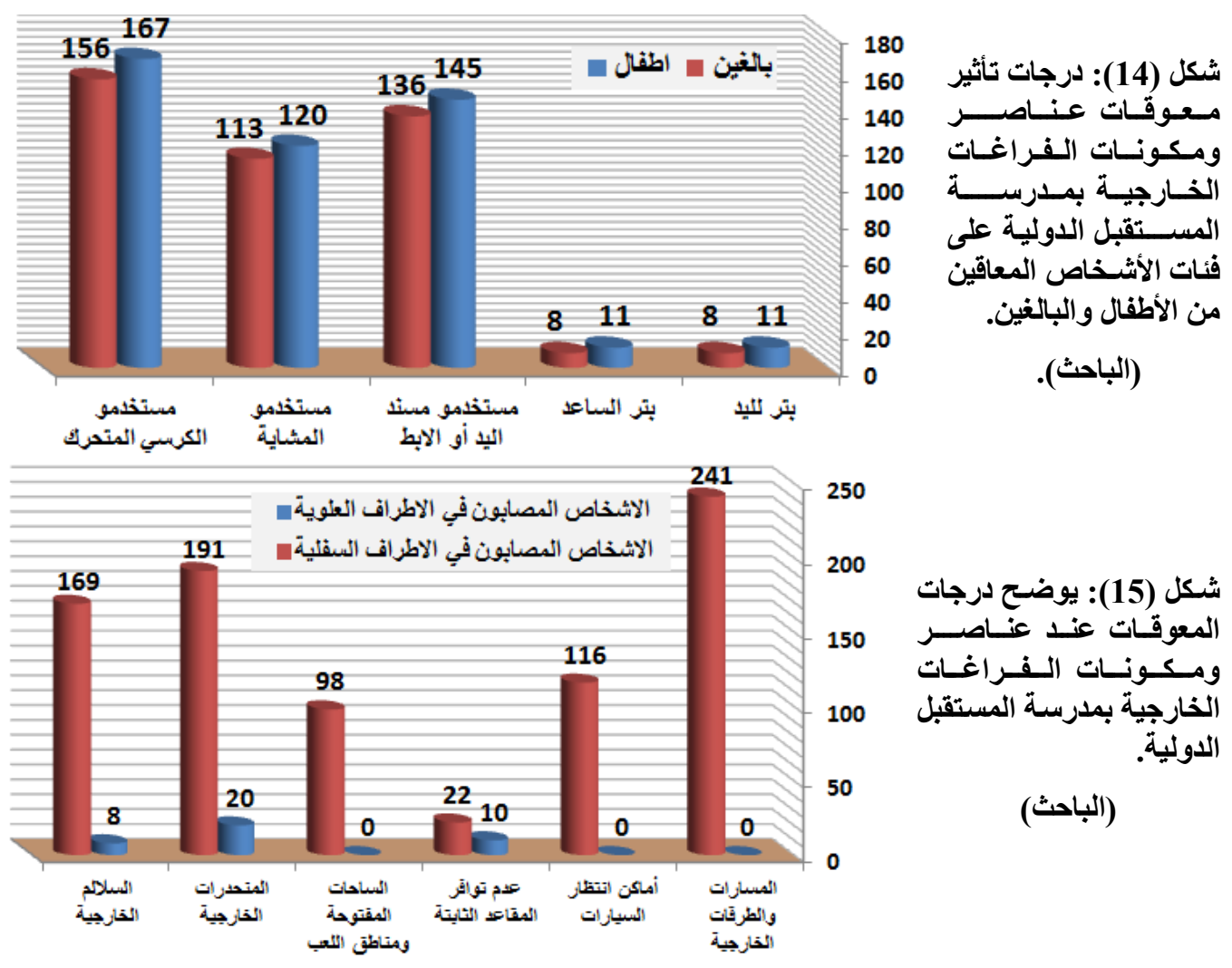

\section{5- التنائج البحثية:}

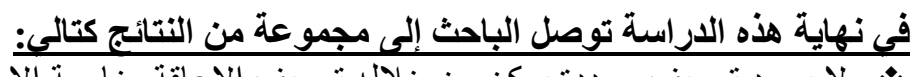

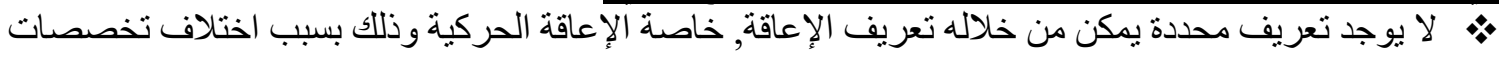
العاملين في مجال رعاية المعاقين. • تثبير الإحصاءات الرسمية في مصر أن نسبة الأشخاص المعاقين حو الي 10.67\% من السكان, اكثريتهم من الأشخاص ذوي الإعاقة الحركية. • يو اجه الأشخاص المعاقون الكثير من التحديات في البيئة المبنية, و التي تصعب من مشاركتهم في مختلف جو انب الحياة,

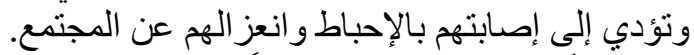

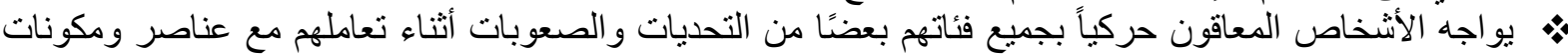

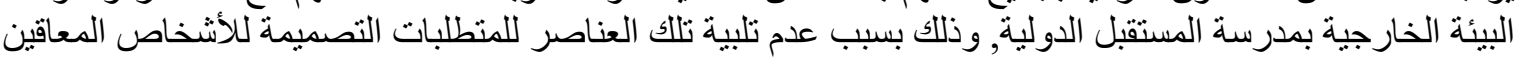
حركيا.

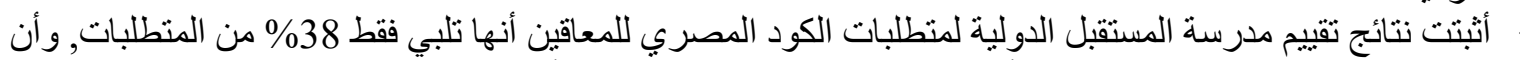

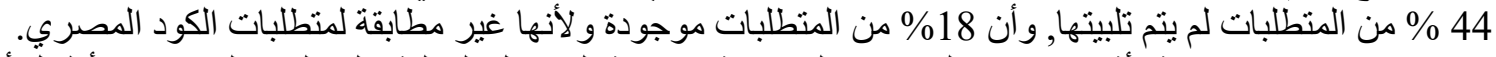

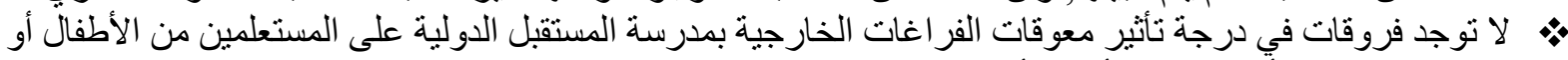
البالغين و إن كان تأثر ها على الأطفال أكبر بقاتيل.

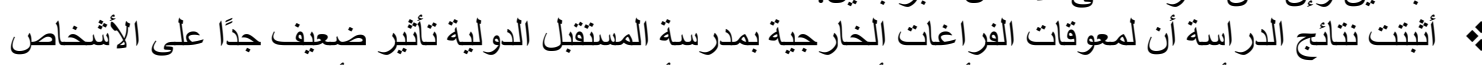

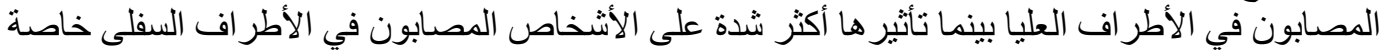
الأشخاص مستعملى الكر اسي المتحركة. 
تقييم ملاءمة الفر اغات الخارجية بالمدارس التعليمية بمصر لذوى الإعاقة الحركية "دراسة حالة: مدرسة المستقبل الدولية بالأقصر"

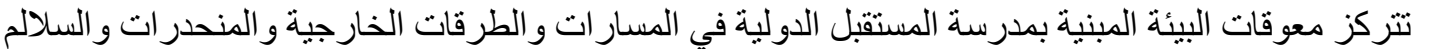

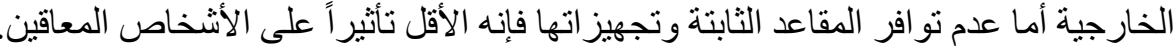

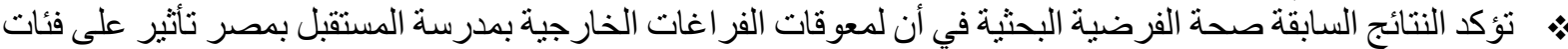

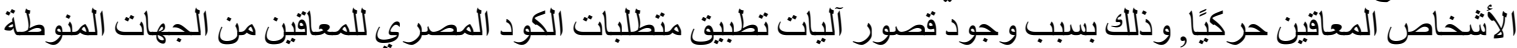

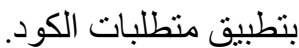

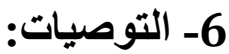

خلص البحث إلى وضع مجموعة من التوصيات التي بمكن من خلالها تحسين البيئة المبنية بأبنية مدارس التعليم في مصر

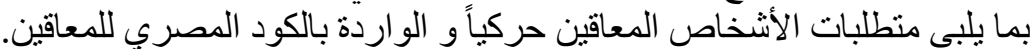

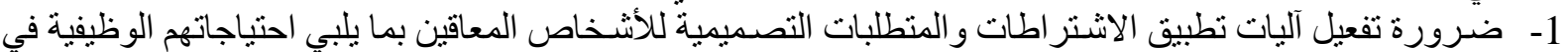

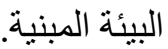

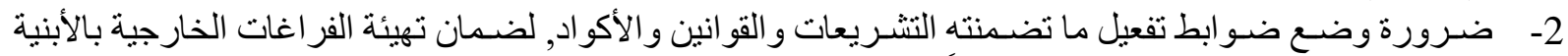

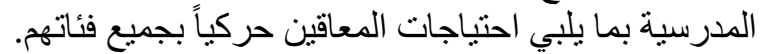
3- التوسـع في الدراسـات و البحوث الأكاديمية التي تتبنى تحديد العلاقة بين البيئة المبنية وفئات الأشخاص المعاقين بصفة

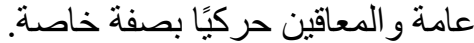
4- ــــرورة إعادة النظر في الأسـاليب المتبعة من قبل الجهات الرقابية لتطبيق اثـتر اطات الكود المصـري للمعاقين في

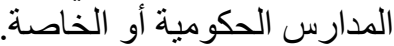
5- تنمية الوعي المجتمعي بحقوق الأشــــاص ذوي الإعي الإعاقة وكيفية التعامل معهم, وذللك عن طريق عقد الندوات وورش العمل و البرامج في وسائل الإعلام و غير ها.

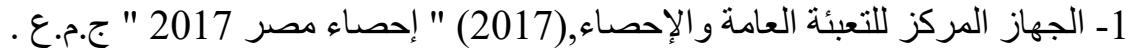

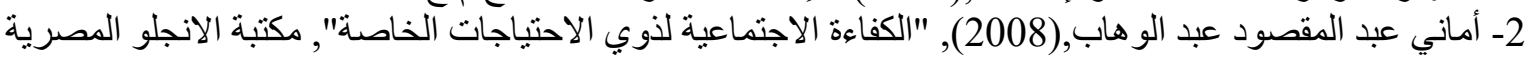
للنشر و ألتوزيع, ج.م.ع.ع.

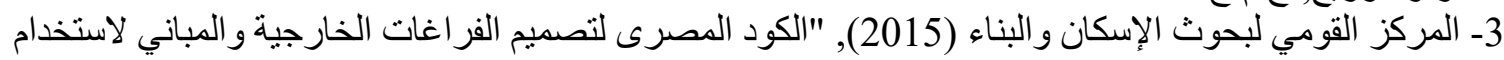

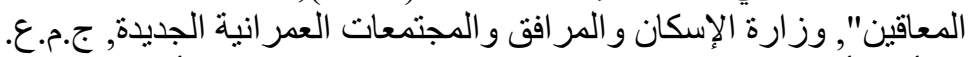

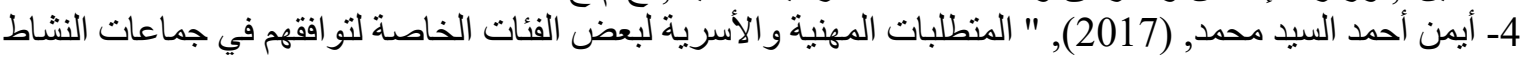
بالمؤسسات الاجتماعية", المكتب الجامعي الحديث. 5- جمال الخطيب,(2005), "مقدمة في الإعاقة السمعية", دار العلوم للتحقيق و الطباعة و النشر و التوزيع.

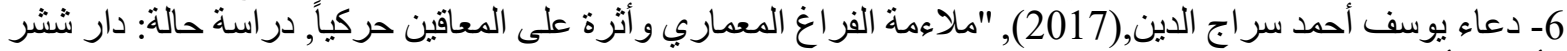

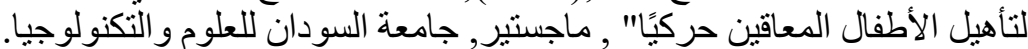
7- صفاء محمود عيسى عبده, (2004)," التصميم بلا عو ائق, دليل المعماري لإنيا لإعداد البيئة للمعاقين جسمياً" , مطابع كلية الإعلام, جامعة القاهرة. 8ـ الجريدة الرسمية المصرية ( 23 ديسمبر 2018), مادة رقم (4) من اللائحة التنفيذية لقانون حقوق الأشخاص ذوي الإعاقة

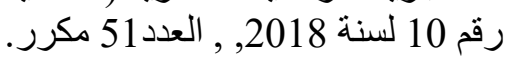
9ـ محمد سيد فهمى,(2005) " التأهيل المجتمعي لذوي الاحتئياجات الخاصة", المكتب الجامعي الحديث.

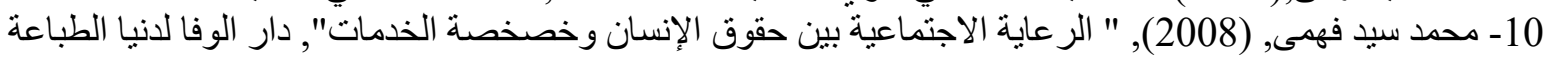
و النشر, الإسكندرية.

11- مختار محمد سعيد الثيبياني,(1994), "المعايير التصميمية للمعوقين حركيًا في البيئة العمر انية", المحمودية, جدة. 12- ISO(2001), Accessibility and Usability of The Built Environment" 13- Government of Dubai,(2017), " Design Dubai Universal Code". 14- Krahn, Gloria L.(2011) "WHO World Report on Disability: a review." Disability and health journal 4.3 .

15- MacKay, Don, (2006). "The United Nations Convention on the rights of persons with disabilities." Syracuse J. Int'l L. \& Com.

16- Prince Salman Center for Disability Research, (2010), "Universal Accessibility Built Environment Guidelines", Kingdom of Saudi Arabia.

17- Steinfeld, Edward, and G. Scott Danford.(1999), "Theory as a basis for research on enabling environments." Enabling Environments. Springer, Boston, MA.

18- United States.(2010), "ADA Standards for Accessible Design". (2010). 
تقييم ملاءمة الفر اغات الخارجية بالمدارس التعليمية بمصر لذوى الإعاقة الحركية "دراسة حالة: مدرسة المستقبل الدولية بالأقصر"

19-Talay, Likden, Nevin Akpinar, and Nur Belkayali.(2010), "Barriers to playground use for Children with Disabilities: A case from Ankara, Turkey." African Journal of Agricultural Research 5.9 